Revista de Estudios Histórico-Jurídicos

[Sección historia del derecho chileno]

XLII (Valparaíso, Chile, 2020)

[pp. 603- 633]

\title{
LA REGULACIÓN DE LOS SERVICIOS DE LOS CRIADOS domésticos EN El Código de Bello. ANÁlisis de sus FUENTES NORMATIVO-DOGMÁTICAS*
}

[The regulation of the domestic service in Bello's Code. Analysis of its regulatory-dogmatic sources]

\author{
Gonzalo SEVERIN FusTer** \\ Pontificia Universidad Católica de Valparaíso, Chile
}

\begin{abstract}
RESUMEN
Este trabajo contribuye a identificar las fuentes normativo-dogmáticas de la regulación de los servicios de criados domésticos que contenía el Código Civil de Bello en su texto original. Luego de analizar la justificación de la concepción contractual de la relación amo-criado, incluyendo la nomenclatura utilizada (I), el resto del trabajo estudia sus reglas, y analiza sus posibles fuentes. Para ello, primero se analiza y concuerda la regulación del Código de Bello con la de los distintos Proyectos de Código Civil (II); luego, se analizan las notas del propio Bello (III), y finalmente se estudian las fuentes normativo-dogmáticas que el Mensaje del Código Civil refiere como base de la regulación en materia de obligaciones y contratos, esto es, la legislación vigente en Chile, los códigos extranjeros y la doctrina de los autores.
\end{abstract}

\section{Palabras Clave}

Arrendamiento - servicios - amos y criados - codificación - siglo XIX - trabajo doméstico.

\section{Abstract}

This paper contributes to identify the normative and dogmatic sources of regulation that contained the original text of the Chilean Civil Code related to the services of domestic servants. After analyzing the justification of the contractual conception of the master-servant relationship (including the nomenclature used) (I), the rest of the work studies its rules, and analyzes its possible sources. With this purpose, the regulation of the Bello's Code is analyzed and compared with that of the different Civil Code Projects (II); Then, the notes of Bello himself are analyzed (III), and finally, the normative and dogmatic sources that the Mensaje of the Civil Code refers to as the basis the Law of contract are studied (the current legislation in Chile, foreign codes and the doctrine of the authors).

$$
\begin{aligned}
& \text { KEY Words } \\
& \text { Lease - service contracts - masters } \\
& \text { and servants - codification - XIX century } \\
& \text { - domestic work }
\end{aligned}
$$

RECIBIDO el 10 de noviembre de 2019 y ACEPTADO el 17 de abril de 2020

* Este trabajo se ha realizado en el marco de ejecución del Proyecto FONDECYT de Iniciación 11170287, del cual el autor es investigador responsable.

** Profesor de Derecho civil de la Pontificia Universidad Católica de Valparaíso. Dirección postal: Avenida Brasil 2950; Valparaíso (Chile). Dirección electrónica: gonzalo.severin@pucv.cl 


\section{INTRODUCCIÓN}

\section{Objeto, finalidad y justificación del estudio}

El Código Civil chileno contiene varias reglas -todas formalmente vigentesque presuponen la existencia de una relación entre un criado (o sirviente) y su amo. Así, el artículo 73 CC (para establecer el domicilio del criado) ${ }^{1}$; el artículo $815 \mathrm{CC}$ (que incluye a los sirvientes en la noción de $\mathrm{f} \mathrm{a} \mathrm{m}$ i $\mathrm{l}$ i a a la que se atiende para determinar el alcance del derecho de uso y habitación) ${ }^{2}$; los artículos 2015 y 2018 CC (que establecen responsabilidad del acarreador y del que contrató el transporte, respectivamente, por el hecho de sus sirvientes) ${ }^{3}$, el artículo 2322 CC (que hace responsable al amo por el delito o cuasidelito de sus criados o sirvientes) ${ }^{4}$; y el artículo 2243 CC (que establece responsabilidad del posadero por el hurto o robo cometido por sus sirvientes) ${ }^{5}$. Todas esas reglas, como se ha dicho, presuponen una relación entre el amo y el criado, relación que el Código Civil chileno de 1855 reguló específicamente al interior del párrafo 7 del título XXVII del Libro IV [Del arrendamiento de criados domésticos (art. 1987 y ss.)]; cuyo contenido fue parcialmente derogado en el año 1931, al entrar en vigor el primer Código del Trabajo ${ }^{6}$.

El estudio de la regulación de la relación jurídica entre amos y criados no ha

${ }^{1}$ Art. 73 Código Civil de Chile [en adelante CC]: "[...] El domicilio de una persona será también el de sus criados y dependientes que residan en la misma casa que ella; sin perjuicio de lo dispuesto en los dos articulos precedentes".

${ }^{2}$ Art. 815 CC: "[inc. $1^{\circ}$ ] El uso y la habitación se limitan a las necesidades personales del usuario o del habitador. [inc. $2^{\circ}$ ] En las necesidades personales del usuario o del habitador se comprenden las de su familia. [inc. $3^{\circ}$ ] La familia comprende al cónyuge y los hijos; tanto los que existen al momento de la constitución, como los que sobrevienen después, y esto aun cuando el usuario o el habitador no esté casado, ni haya reconocido hijo alguno a la fecha de la constitución. [inc. 40] Comprende asimismo el número de sirvientes necesarios para la familia [...]". Esta noción de familia, que comprende a los criados, encuentra su fuente en Partidas 7, 33, 6, que señala "por esta palabra familia se entiende el señor de ella y su mujer y todos los que viven bajo él sobre quien ha mandamiento: asi como los hijos, y los sirvientes, y los otros criados".

${ }^{3}$ Art. 2015 CC: "[inc. $1^{\circ}$ ] El acarreador es responsable del daño o perjuicio que sobrevenga a la persona por la mala calidad del carruaje, barco o navio en que se verifica el transporte. [inc. $2^{\circ}$ ] Es asimismo responsable de la destrucción y deterioro de la carga, a menos que se haya estipulado lo contrario, o que se pruebe vicio de la carga, fuerza mayor o caso fortuito. [inc. $3^{\circ}$ ] $Y$ tendrá lugar la responsabilidad del acarreador no sólo por su propio hecho, sino por el de sus agentes o sirvientes". Por su parte, el art. 2018 CC, señala: "El que ha contratado con el acarreador para el transporte de una persona o carga, es obligado a pagar el precio o flete del transporte y el resarcimiento de daños ocasionados por hecho o culpa del pasajero o de su familia o sirvientes, o por el vicio de la carga".

${ }^{4}$ Art. 2322 CC: "[inc. $1^{\circ}$ ] Los amos responderán de la conducta de sus criados o sirvientes, en el ejercicio de sus respectivas funciones; y esto aunque el hecho de que se trate no se haya ejecutado a su vista. [inc. $2^{\circ}$ ] Pero no responderán de lo que hayan hecho sus criados o sirvientes en el ejercicio de sus respectivas funciones, si se probare que las han ejercido de un modo impropio que los amos no tenian medio de prever o impedir, empleando el cuidado ordinario, y la autoridad competente. En este caso toda la responsabilidad recaerá sobre dichos criados o sirvientes".

${ }^{5}$ Art. 2243. "El posadero es además obligado a la seguridad de los efectos que el alojado conserva alrededor de sí. Bajo este respecto es responsable del daño causado o del hurto o robo cometido por los sirvientes de la posada, o por personas extrañas que no sean familiares o visitantes del alojado".

${ }^{6}$ El artículo 174 del Decreto con Fuerza de Ley N. 178, de 13 de mayo de 1931 (D.O. 14 
recibido especial atención por parte de la doctrina jurídica nacional. En efecto, no conocemos trabajos específicos sobre ello en estudios de carácter histórico-jurídicos. Tampoco la doctrina civilista le ha prestado atención; de hecho, ni siquiera se trata en los textos generales sobre el contrato de arrendamiento ${ }^{7}$. Y, en los casos en los que hace alguna referencia a esa regulación, se asume, acríticamente, que ella está derogada, o sin aplicación, como consecuencia de la irrupción del Derecho laboral ${ }^{8}$, haciendo eco de la opinión generalizada de la doctrina laboralista ${ }^{9}$. En los textos de Derecho laboral, se agrega además, en tono de crítica, el carácter clasista de la regulación, y su perspectiva denigrante o discriminadora hacia el criado; ello, tanto por la nomenclatura utilizada (amos y criados) ${ }^{10}$, como por la existencia de

de mayo de 1931), por el que entró el vigor el primer Código del Trabajo, derogó los artículos 1987 a 1991; dejando en vigor los artículos 1992 a 1995.

${ }^{7}$ Por ejemplo, en OrRego Acuña, Juan Andrés, El contrato de arrendamiento (2a ed., Santiago, Ed. Metropolitana, 2011), si bien se dedican unas páginas a los arrendamientos de servicios y obra, sólo lo hace, como el propio autor sostiene, "en términos generales" (p. 16), y les dedica los dos últimos capítulos de su libro (pp. 453-481); pero, únicamente se refiere al arrendamiento de confección de obra y de servicios inmateriales, y no aborda (sin explicar las razones de esa omisión) ni el párrafo dedicado a los criados domésticos, ni el párrafo dedicado al contrato de transporte.

${ }^{8}$ Así, por ejemplo, por ejemplo, Erbetta Mattig: "las normas sobre arrendamiento de criados domésticos, [...] se encuentran actualmente derogadas y sin aplicación"; y en nota agrega "El arrendamiento de criados domésticos s e e n c o n t r a b a regulado entre los arts. 1987 y 1995 del CC", como se ve, utilizando el tiempo pasado, pese a que parte de esos artículos están formalmente en vigor [ERBetTA MATTIG, Andrés, La cesación unilateral del contrato de obre prevista en el art. 1999 inc. 2 del Código Civil, en Revista Chilena de Derecho Privado, 28 (2017), p. 20 (destacado añadido)].

9 "Hoy día los preceptos del Código Civil sobre criados domésticos están derogados por el Código del Trabajo, que reglamenta el contrato con aquellos asalariados" [WALKER LINARES, Francisco, Esquema del derecho del trabajo y de la seguridad social en Chile (Santiago, Editorial Jurídica de Chile, 1965), p. 54]. "En cuanto al contrato de arrendamiento de servicios inmateriales y al contrato de arrendamiento de criados domésticos, las disposiciones del Código Civil han p e r d id o i m p o r ta n cia, debido a la legislación del trabajo. Ambos corresponden por sus características a simples contratos de trabajo, en el que el arrendatario equivale al patrón o empleador de hoy" [LABARCA GODDARD, Eduardo, El concepto de patrón o empleador en la legislación chilena (Santiago, Editoral Jurídica de Chile, 1966), p. 63 (destacado añadido)]. Esta última afirmación es especialmente temeraria, en lo relativo al arrendamiento de servicios inmateriales, pues las normas se aplican, actualmente, a las relaciones de trabajo que no satisfacen los criterios de aplicación del Código del Trabajo. Por su parte, Thayer ArTEAGa sostiene que "[este párrafo está] en parte derogado en forma explícita y en parte sin aplicación, según expresa nota de la edición oficial, pese a que, en nuestra opinión, se trata de una derogación tácita de todo el párrafo" [Thayer ARTEAGa, William, El trabajador en la historia del derecho laboral chileno, en Revista Chilena de Derecho, 16/3 (1989), p. 765]. Sin perjuicio de todas estas afirmaciones, a mi juicio, parece necesario un estudio más detenido acerca de la supuesta derogación tácita de las normas del párrafo sobre arrendamiento de criados domésticos que siguen formalmente vigentes (cómo y cuándo se produjo), porque no parece lógico sostener que la misma ley que derogó expresamente una parte, haya derogado tácitamente el resto. Esta es tarea pendiente.

10 "En primer término, el solo título del párrafo que regula la situación de estos trabajadores tiene un aspecto vejatorio, puesto que se habla del «arrendamiento de criados domésticos» como sí se hablara del arrendamiento de una cosa. Ninguno de los demás títulos de esta sección tiene la misma connotación, puesto que no se habla del «arrendamiento de artesano», sino de 
ciertas reglas que favorecen al amo, específicamente, la regla del artículo 1995 CC (según la cual ha de creerse al amo sobre el criado en relación con el salario y su pago $)^{11}$, aunque todo ello se plantea sin ofrecer un análisis sobre la razón de esas reglas ni sobre sus fuentes, y sin ahondar en su contexto histórico.

Un estudio detenido de la regulación del párrafo sobre el "arrendamiento de criados domésticos" del Código Civil de Bello, que ahonde en sus fuentes normativo-dogmáticas y en sus fuentes materiales, parece, entonces, justificado y necesario. Este trabajo tiene como finalidad precisa contribuir en este estudio. Específicamente, lo que se propone es determinar cuáles fueron las fuentes normativo-dogmáticas de esta regulación, de modo de poder explicar el particular contenido de las reglas que originalmente componían el párrafo 7 del título XXVI del Libro IV. El estudio resulta adicionalmente útil, porque, como se ha indicado, esa regulación refiere a una relación jurídica cuyos efectos se proyectan más allá de las normas que componen ese párrafo (en otras normas que, como se ha indicado, suponen la relación amo-criado) y cuya vigencia no se ha discutido (por ejemplo, en el ya referido artículo 2322 del Código Civil ${ }^{12}$; pero también fuera del Código Civil, en el artículo 447 del Código Penal ${ }^{13}$; y en el artículo 358 del Código de Procedimiento Civil $\left.{ }^{14}\right)$. La adecuada comprensión de la figura del "arrendamiento de criados domésticos" permite, entonces, comprender el alcance y, a partir de ahí, discutir la vigencia de esas otras normas (partiendo de la base de

"contrato para la confección de una obra material», o bien del arrendamiento de «servicios inmateriales», o de "transporte», pero nunca del arrendamiento de una persona. La normativa establecida denota la falta de consideración y respeto social del Código hacia la "servidumbre»" [GonzÁlez Le SAux, Marianne, Tienda, botica, fábrica, taller, posada y escuela. La clase media en las disposiciones patrimoniales del Código Civil chileno de 1855, en Estudios de la República (Universidad de Chile, 2011), p. 28]. En el mismo sentido, WaLKer: "en ese Código [el Civil], que está totalmente dominado por el principio de la absoluta autonomía de la voluntad o libertad contractual, sólo se alude al trabajo asalariado de una manera secundaria, al tratarse del arrendamiento de criados domésticos, usándose de la terminología denigrante de amos y criados [WalKer LinAREs, Francisco, cit. (n. 9) p. 53].

${ }^{11}$ Así, por ejemplo, WALKER LINARES: "se alude al trabajo asalariado de una manera secundaria [...] estableciendo en su artículo 1995 una presunción legal a favor del amo respecto a la cuantía y el pago del salario; este criterio despectivo para el trabajador era el que imperaba a mediados del siglo [XIX]" [cit. (n. 9) p. 53]. En el mismo sentido, Humeres Noguer, afirma que "da ciertas normas que hasta hoy día se han repetido en nuestra legislación, como el desahucio [...] pero también consagraba otras evidentemente favorables al patrón o amo, como la del artículo 1995, que establecía presunción legal, respecto a lo que declaraba el amo en cuanto a la cuantía del salario, al pago del mes y a los anticipos" [Humeres nOGUER, Héctor, Apuntes de derecho del trabajo y de la seguridad social (10ª ed., Santiago, Editorial Jurídica de Chile, 1973) p. 53].

${ }^{12}$ Véase, supra, nota 4.

${ }^{13}$ Art. 447 Código Penal: “[inc. 1º En los casos del artículo anterior podrá aplicarse la pena inmediatamente superior en grado: $1 .^{\circ}$ Si el hurto se cometiere por dependiente, criado o sirviente asalariado, bien sea en la casa en que sirve o bien en aquella a que lo hubiere llevado su amo o patrón [...]". El 3 de octubre de 2013 se presentó un proyecto de ley, iniciado en moción del senador señor Orpis, que suprimía las palabras “amo” y “criado" de este artículo. Dicho proyecto fue archivo en el año 2018.

${ }^{14}$ Art. 358 Código de Procedimiento Civil: "[inc. $1^{\circ}$ ] Son también inhábiles para declarar: [...] $4^{\circ}$. Los criados domésticos o dependientes de la parte que los presente". 
que en la actualidad no existe la relación social de amo-criado); lo que, de paso, permite una mejor comprensión del modelo de regulación legal vigente de los contratos de prestación de servicios en el Código Civil chileno.

\section{Metodología y plan de exposición}

Este trabajo toma como punto de partida la propia explicación que se ofrece en el Mensaje del Código civil, en relación con las fuentes utilizadas en materia de derecho de obligaciones y contratos. En este punto, el Mensaje expresa que, "en materia de contratos y cuasicontratos, hallaréis muy poco que no tenga su fuente en la legislación actual, que es lo más, o en la autoridad de un código moderno, en especial el francés, o en la doctrina de alguno de los más eminentes jurisconsultos". Sin embargo, de inmediato se señala que, además, "se ha tenido muy presente en algunos contratos, como el de arrendamiento, la práctica del pais, cuyas especialidades ha parecido exigir disposiciones peculiares". Como se puede observar, la primera referencia general es las que podemos denominar fuentes dogmático-normativas, y de ellas, como se ha dicho, nos ocuparemos en este trabajo. La consideración de la "práctica del país" parece evocar las fuentes materiales, cuyo análisis supone estudiar las características de la relación amo-criado de la primera mitad del siglo XIX desde una perspectiva social; ello excede el objeto de estudio de este trabajo y del análisis propiamente jurídico, si bien alguna referencia resulta ineludible.

El trabajo se divide en cuatro partes, y sigue el siguiente plan de exposición. En la p ri m e r a pa r t e se da cuenta de la aproximación del Código Civil en relación con la estructura o forma de la regulación, esto es, el tratamiento de las relaciones amo-criado como un contrato, y específicamente, como un contrato de arrendamiento. De paso, se da cuenta de la nomenclatura utilizada en el texto para designar a las partes. Tras ello, el trabajo analiza las reglas que componen la regulación del arrendamiento de los criados domésticos en el Código de Bello. Así, en la s e g u n d a p a r t e, se enuncian esas reglas, las que son concordadas con las que se contenían en los diversos proyectos de Código Civil. Tal ejercicio sirve a dos fines. Por un lado, permite identificar si, en algunos de esos textos, hay o no referencias o notas de Bello, que pudieran considerarse indicios de las fuentes normativo-dogmática utilizadas; de ello -y especialmente, del análisis de las fuentes referidas en las notas- trata la t e r c e r a parte del trabajo ${ }^{15}$. Por otro lado, ese ejercicio de análisis y comparación entre los diferentes proyectos, y el texto definitivo del Código Civil, permite identificar el momento en que, dentro del proceso codificador, cada particular regla fue introducida, cuestión que es clave a la hora de determinar sus posibles fuentes normativo-dogmáticas de entre las

\footnotetext{
${ }^{15}$ Este análisis parece especialmente relevantes, considerando, la inexistencia de actas oficiales de las sesiones de la Comisión Revisora del Código Civil [ $c f r$. GuZMán Brito, Alejandro, Algunas actas de sesiones de la comisión revisora del Código Civil, en Revista de Estudios Histórico-Jurídicos, 5 (1980), p. 413-418]; ello, sin perjuicio que se ha sugerido que hay antecedentes suficientes para entender que sí se llevaron actas, las que permanecieron inéditas [SALINAS ARANEDA, Carlos, Notas en torno a las actas de los proyectos de Código Civil, en Revista de Derecho de la Pontificia Universidad Católica de Valparaíso, 1 (1977), p. 39 y ss.].
} 
varias fuentes a las que refiere el Mensaje; de ello trata la c u a r t a pa r t e del trabajo. Al final, se recogen las principales c o n clu s i o n e s.

\section{El SERVICIO DE LOS CRIADOS COMO UNA FORMA DE ARRENDAMIENTO. LA} ESTRUCTURA DE LA REGULACIÓN, Y LA NOMENCLATURA UTILIZADA

Como ya se ha anunciado, el Código Civil chileno reguló las relaciones entre los amos y los "criados domésticos" dentro del título dedicado al contrato de a r r e n d a m i e n t o (Libro IV, título XXVII, art. 1915 y ss.); a los que dedica un párrafo (párrafo 7, art. 1987 y ss. CC), al igual que hace con otras relaciones contractuales cuya finalidad económica, determinada a partir de la prestación característica del contrato, difiere de la cesión temporal del uso de una cosa a cambio de un precio (arrendamiento de cosa) y que más propiamente pueden ser calificables como de prestación s e r v i c i o s ["los contratos para la confección de obra material" (art. 1996 y ss.), "el arrendamiento de servicios inmateriales" (art. 2006 y ss.) y el "arrendamiento de transporte" (art. 2013 y ss.)]. La definición legal de arrendamiento, contenida en el artículo 1915 del Código Civil, es consistente con esa concepción que podríamos denominar "amplia" del arrendamiento, que admite arrendar cosas, por un lado, y obras y servicios, por otro ${ }^{16}$.

¿Qué es lo que explica esta aproximación adoptada por el Código Civil? En síntesis, ella obedece a la conservación de un modelo jurídico de raigambre romana, el de la locatio conductio, contrato bajo el cual quedaban comprendidas una serie de finalidades económicas que, al menos hoy, consideramos muy diversas: la locatio conductio engloba tanto la cesión temporal del uso de la cosa a cambio de dinero, como la prestación de ciertos servicios remunerados. Es sabida la importancia que, para Bello, tiene el derecho romano ${ }^{17}$; pero hay que considerar que la adopción de este modelo no es consecuencia de un recurso directo al derecho romano, y se explica porque esa aproximación subsistió por siglos, y estaba presente en las dos fuentes más importantes del Código Civil en esta materia: el Code francés de 1804, y Las Partidas ${ }^{18}$.

Se ha sugerido que esa unidad conceptual, que permitió bajo un mismo contrato (locatio conductio) dar cabida también a la confección de obras y a la prestación de servicios en general, puede explicarse como el resultado de una proyección evolutiva, desde una figura inicial, que es la cesión temporal de una cosa material con una finalidad precisa, usarla (locatio conductio rei), que se extiende a otras finalidades, como transformarla, transportarla, limpiarla, etc.

${ }^{16}$ Artículo 1915 CC: "El arrendamiento es un contrato en que las dos partes se obligan reciprocamente, la una a conceder el goce de una cosa, o a ejecutar una obra o prestar un servicio, y la otra a pagar por este goce, obra o servicio un precio determinado".

${ }^{17}$ Es conocida la relevancia que, para Bello, tiene el derecho romano; para una breve exposición de las fuentes romanas del Código Civil, véase, JAKSIC, Iván, Andres Bello: la pasión por el orden ( $3^{\mathrm{a}}$ ed., Santiago de Chile, Editorial Universitaria, 2010) pp. 222-226.

${ }^{18}$ Sobre la forma en que se recoge el modelo de regulación de la locatio conductio en el Código Civil francés y en las Siete Partidas, véase SEVERIN Fuster, Gonzalo, La recepción del modelo de la locatio conductio en la regulación del "arrendamiento de obras y servicios" del Código civil español de 1889, en Revista de Estudios Histórico-Jurídicos, 38 (2016), pp. 201-223. 
(locatio conductio operis) y a otras c o s a s: la cesión de un esclavo (una cosa), y desde ahí, al trabajo del liberto y luego también al del hombre libre (que se cede a sí mismo, su esfuerzo o el producto de su trabajo en forma temporal; locatio conductio operarum $)^{19}$. La consideración de esta perspectiva histórica permite sugerir que la crítica que se hace a la denominación del párrafo sobre "arrendamiento de criados domésticos", de ser especialmente ignominiosa o vejatoria (los criados domésticos aparecerían como o b j e t o del contrato, y no s u j e t o s ) ${ }^{20}$, no es especialmente atendible; $y$, de hecho, esa crítica puede disolverse mediante un simple recurso gramatical, pues bien puede entenderse que el arrendamiento de criados domésticos es el arrendamiento que celebran los criados domésticos. Por lo demás, el artículo que abría el párrafo, el artículo 1987 del Código Civil, dejaba en claro que el criado era una parte del contrato ("En el arrendamiento de criados domésticos una de las partes promete prestar a la otra, mediante un salario, cierto servicio, determinado por el contrato o por la costumbre del país”), por tanto, es evidentemente sujeto y no objeto.

Es posible afirmar, por tanto, que, desde el punto de vista de la e s t r u c t u r a de la regulación, Bello no innovó, pues simplemente conservó (tal como ocurre en el Code y Las Partidas) la aproximación romana, que consideraba toda contratación de servicios, en cuanto prestación remunerada, como una forma de arrendamiento; incluyendo los servicios personales ${ }^{21}$. De hecho, en el proceso de codificación civil chileno no hay ningún antecedente que permitan sugerir, siquiera, que se haya considerado abordar las relaciones amo-criado desde otra perspectiva $(v$. gr.: normas de policía sobre el orden de las familias, o normas relativas al estado de

${ }^{19}$ Sobre el contrato de la locatio conductio, con especial referencia a la cuestión de la tripartición (rei, operis, operarum), en la doctrina romanista, véase SEVERIN FusTer, Gonzalo, Sobre el modelo de contratación de servicios remunerados en el derecho romano. Algunos aspectos relevantes de la locatio conductio, en Revista de Derecho de la Universidad Católica del Norte (RDUCN), 22/2 (2015), pp. 357-389.

${ }^{20}$ Véase, supra, n. 10.

${ }^{21}$ De ahí que, en el Código Civil de Bello, siguiendo también el modelo romano, el depósito voluntario (que es un contrato esencialmente gratuito) degenere en un arrendamiento de servicios cuando es remunerado ( $c f r$. art. 2219 inciso $2^{\circ} \mathrm{CC}$ ), idea que también recoge la aproximación romana sobre la distinción entre ambos contratos [sobre la delimitación conceptual entre la locación y el depósito, en el derecho romano; SEVERIN Fuster, Gonzalo, Sobre, cit. (n. 19) pp. 363-364; y en las Partidas y el Code Civil, Severin Fuster, cit. (n. 18) p. 206 y pp. 212-215]. También en el derecho romano, se entiende que la gratuidad esencial del mandato justifica su tratamiento separado de la locatio conductio; y ello, aun cuando después se admitiera una remuneración, que se llamó precisamente "honorario", para diferenciarla de la "merces"; así lo recoge el propio Bello en sus Instituciones de derecho romano: "Los servicios de los abogados, médicos, agrimensores y demás personas que nos sirven con su ciencia y crédito, no se reputan materia de este contrato, y su recompensa se llama honorario" [BELLo, Andrés, Obras completas. Vol. XVII. Derecho Romano (2a ed., Caracas, Fundación La Casa de Bello, 1981)]. La pérdida del carácter gratuito del mandato hizo que esa distinción se difuminara, y se tuviera que recurrir a otros criterios [sobre ello, véase, por ejemplo, SeVERIN Fuster, Gonzalo, Sobre, cit. (n. 19) pp. 364-365]. Véase también, infra, nota 27. 
las personas), como sí ocurrió, por ejemplo, en Colombia ${ }^{22}$ o en España ${ }^{23}$ (si bien ambos países igualmente terminaron por regular las relaciones amo-criado como formas de arrendamiento, siguiendo el modelo tradicional romano $)^{24}$.

Finalmente, no ha de perderse de vista que esa aproximación adoptada, consistente en tratar estas relaciones bajo una lógica contractual, esto es, entre partes que se consideran jurídicamente iguales, está igualmente en sintonía con el liberalismo chileno del siglo XIX ${ }^{25}$. De hecho, el propio Bello -sin negar que es

${ }^{22}$ Cfr. Solano, Sergio, Entre el Código Civil y el Código de Policía. Trabajo, orden doméstico y legislación laboral en el Caribe colombiano en el siglo XIX, en Revista Gaceta Laboral, 16/2 (2010), pp. 154-155.

${ }^{23}$ En este sentido, conviene destacar la aproximación del Proyecto de Código Civil español de 1821, del que sólo se imprimió y publicó una parte: el título preliminar y los libros I y II de la primera parte. Precisamente en esa primera parte, existe referencia a los criados domésticos, primero, en el Libro I, título III (De la pérdida, suspensión y preservación de los derechos) que ofrece una definición de sirviente doméstico, con la finalidad acotada que se señala ["Art. 79. Se reputa sirviente doméstico para los efectos del articulo 25 de la Constitución el que presta servicios puramente mecánicos en favor de otras personas, como objeto principal de su ocupación. La ley no considera por servicios mecánicos las labores del campo, el ejercicio de las artes, oficios, comercio y otro cualquier género de industria ó grangería; la enseñanza y educación de la juventud; el empleo en oficinas de administración, contabilidad ú otros semejantes]; y luego, se regulan los servicios de los "jornaleros y criados domésticos", en el Libro II (De los derechos y de las obligaciones según la diferente condición doméstica de las persona, en título IV (De la condición de superior y dependiente), específicamente, en los artículos 455-476 [cfr. Lasso Gaite, Juan Francisco, Crónica de la Codificación Española IV: Codificación civil (Génesis e historia del Código) (Madrid, 1970), II/1-2, p. 21 ss.]. Un reciente e interesante análisis de este Proyecto de Código Civil español de 1821, con varias referencias a la cuestión de la dependencia doméstica, en PeTrT, Carlos, Un Código Civil perfecto y bien calculado. El proyecto de 1821 en la historia de la codificación (Madrid, Dykinson, 2019).

${ }^{24}$ En el caso del derecho español, el Código Civil considera, al igual que el derecho chileno, una regulación del arrendamiento de criados domésticos, que se denomina "del servicio de criados y trabajadores asalariados" (art. 1583 y ss.), dentro del capítulo III (Del arrendamiento de obras y servicios), del título dedicado al contrato de arrendamiento. La doctrina española considera, en general, que dichas normas no están vigentes; y acusa, como ocurre en la doctrina chilena, que se trata de normas desfasadas de la realidad, discutiendo su vigencia. En este sentido, por ejemplo, Torres Lana, afirma que esa regulación es "buena muestra de normativa arcaica, absolutamente desfasada de la realidad actual, a la par que expresiva de los postulados ideológicos que inspiraron el CC. Es posible poner en tela de juicio la vigencia de la sección entera [...] desde luego, no cabe duda de que sus normas han sido superadas en todos los aspectos: políticos, jurídicos y sociales. Sin embargo, los artículos que la integran siguen ahí: no han sido objeto de derogación expresa" [Torres Lana, José Ángel., Comentarios de los art. 1583-1587, en PAZ-Ares, Cándido et al. (dirs.), Comentario del Código Civil (Madrid, Ministerio de Justicia, 1993) pp. 1170]. En el caso del derecho colombiano, la regulación original del Código Civil siguió estrechamente la del Código de Bello; regulando las relaciones en un capítulo al interior de la regulación del arrendamiento, bajo el nombre "Del arrendamiento de criados domésticos" (art. 2045 y ss. $\mathrm{CCCol})$. No obstante, todas las normas originales de ese capítulo no están vigentes; pues fueron s u b r o g a d a s por el Código Sustantivo del Trabajo. Es interesante destacar, además, que, en el caso del derecho colombiano, todos los demás artículos del Código Civil que emplean los términos "sirvientes", “criados” o "amos" (artículos análogos a los artículos 73, 815, 2015, 2018, y 2322 CC) han sido declarados i n ex e qu i b l e s por la Corte Constitucional de Colombia; debiendo utilizarse, en su reemplazo, las expresiones "trabajador" y "empleador".

${ }^{25}$ En este punto, como recuerda CAVIERES, "El liberalismo chileno del siglo XIX y, a lo menos hasta mediados de la década de 1920, ha sido denominado como un liberalismo ortodoxo, de muy 
posible entender que existen servicios socialmente considerados más honorables que otros- entiende que, desde el punto de vista de la naturaleza del servicio, no ha de distinguirse sustancialmente entre los que presta un abogado y los de un criado $^{26}$. Adviértase que no se pretende aquí defender la idea de que los criados fueran considerados socialmente iguales a los amos. Es más, ni siquiera es posible predicar una igualdad jurídica entre ellos, pues, si bien la Constitución de 1833 predicaba "La igualdad ante la ley", agregando que "En Chile no hay clase privilegiada" (art. 12 Constitución de 1833), el mismo texto establecía que los criados domésticos no eran "ciudadanos activos con derecho a sufragio" 27 . Tampoco estoy juzgando el contenido de la regulación (de ello me ocupo en otras partes del trabajo). Simplemente apunto a la comprensión de la relación criado-amo como originada en una relación contractual, y no como una relación impuesta al criado. Desde este punto de vista, puede afirmarse que el Código de Bello de 1855 no considera el trabajo remunerado como una realidad social a la que haya que prestar especial atención, ni mira al trabajador como un sujeto que requiera

poca participación del Estado en los ámbitos de la vida privada y de las relaciones económicas. Un liberalismo del laissez faire observable especialmente en términos de una legislación social o más particularmente, de una legislación laboral. Efectivamente, no hubo legislación social en una economía que distaba de ser moderna y en donde las relaciones y nuevas estructuras sociales recién comenzaban a configurarse en un nuevo sistema de clases" [CAVIERES FIGUEROA, Eduardo, Liberalismo: ideas, sociedad y economía en el siglo XIX (Valparaíso, Ediciones Universitarias de Valparaíso, 2016), p. 88]. Sobre el liberalismo en Chile, en el período de codificación civil, véase, Collier, Simon, Chile. La construcción de una República. 1830-1865. Política e ideas (2a ed., Santiago, Ediciones de la Universidad Católica de Chile, 2008), pp. 171-178.

${ }^{26}$ Sobre el punto, y en general sobre las ideas de Bello en relación con la distinción entre el arrendamiento de servicios y el mandato, véase su trabajo titulado La locación de servicios y el mandato, originalmente publicado, en forma póstuma, en Los Lunes de la época, (Santiago, 1882-1883); recogido en Bello, Andrés, Obras Completas, Obras completas. Vol. XVIII. Temas jurídicos y sociales (2a ed., Caracas, Fundación La Casa de Bello, 1981), pp. 373-381; 467-474. Un estudio sobre las ideas de Bello en relación con el carácter remunerado o gratuito del mandato puede verse en Mondaca Miranda, Alexis, Evolución del pensamiento de Andrés Bello sobre el carácter gratuito u oneroso del contrato de mandato, en Revista de Estudios Histórico-Jurídicos, 41 (2019), pp. 317-340.

${ }^{27}$ En efecto el artículo 10 de la Constitución Política de 1833 señalaba que "se suspende la calidad de ciudadano activo con derecho de sufragio", entre otras causas, por "la condición de sirviente doméstico". De ahí que, sin perjuicio de esas declaraciones constitucionales sobre la igualdad, la afirmación del artículo 12 de la Constitución de 1833, de que "en Chile no hay clases privilegiadas", parece una simple declaración de principios, o a lo sumo, una declaración puramente programática, que ni la propia Constitución parecía respetar. El significado que puede atribuirse a tal declaración constitucional requiere un análisis algo más detenido, que considere el contexto político y social de la época; lo que excede el objeto de este trabajo. Con todo, considérese, por ejemplo, el dificultoso proceso de abolición de la esclavitud, que da cuenta de una cierta comprensión de la estructura social de clases, a la que no todos estaban dispuestos a renunciar. El propio Egaña, uno de los principales ideólogos de la Constitución de 1833 , entendía que la aplicación del decreto de 1814 (que prometía la libertad en forma automática a los esclavos que se alistaran en el ejercito patrio) "atentaba contra el derecho de propiedad" y que era "un atropello, un despojo violento, la coacción de un derecho" [FELIU Cruz, Guillermo, La abolición de la esclavitud en Chile. Estudio histórico y social (2a ed., Santiago, Editorial Universitaria, 1973), pp. 74-75]. 
una especial protección; y ello es algo de toda lógica: esas ideas garantistas irrumpen en el discurso social latinoamericano recién hacia fines del siglo XIX ${ }^{28}$. Es la llamada c u e s t i ó n s o c i a l la que exige "cambiar ese indiferentismo legal por la condición de la parte débil del contrato de trabajo"29.

Teniendo en consideración lo anterior, no parece, pues, que pueda criticarse excesivamente que no se usen las expresiones a r r e n d a d o r y a r r e n d a t ar i o, y en cambio, se conserven las expresiones a m o y c r i a d o para designar a las partes del contrato. Bello recogió las denominaciones usuales de la época; y sin perjuicio de la carga social que tales expresiones pudieran conllevar, es claro que el Código Civil, con la expresión a m o , no pretendía indicar que la persona a quien se prestaran los servicios tuviera una suerte de derecho de propiedad sobre el sirviente (y, como se verá, el contenido de la regulación así lo demuestra). En efecto, si recurrimos, por ejemplo, al Diccionario de la Real Academia Española del año $1852^{30}$, del que Bello disponía ${ }^{31}$, podemos apreciar que amo es, simplemente "cabeza o señor de la casa o familia. Paterfamilias"; sirviente, es "el o la que sirve"; servidor, se define como "el que sirve como criado"; y criado, se define, primero, "como el que ha recibido de otro la primera crianza, alimento y educación", y en otra acepción, "el que sirve por su salario". Por último, hay que tener en cuenta que en la lengua castellana la voz c r i a d o , aplicada al sirviente, da cuenta de cómo, tradicionalmente, se había generado esa relación entre el servidor y el señor de casa: muchos sirvientes domésticos habían llegado a serlo, porque, siendo niños, habían sido entregados p a r s e r criados (participio del verbo criar) por otra familia ${ }^{32}$. En Chile, durante la colonia, y después de la Independencia, fue esa también una forma usual -si bien no la única- de reclutamiento de los sirvientes

${ }^{28}$ VIllasamil PRIETO, Humberto, Pasado y presente del derecho laboral latinoamericano y las vicisitudes de la relación de trabajo (primera parte), en Revista Latinoamericana de Derecho Social, 21 (julio-diciembre 2015), esp. pp. 205-207.

${ }^{29}$ Concha, Juan Enrique, Cuestiones obreras, en Grez Toso, Sergio, La "cuestión social" en Chile. Ideas y debates precursores (1804-1922), (Santiago, Dirección de Bibliotecas, Archivos y Museos, 1995), pp. 456-517 (originalmente publicado por Imprenta, Litografía y encuadernación Barcelona, Santiago, 1889). El mismo autor, plantea: "no se hace diferencia alguna entre la situación del arrendador y arrendatario de servicios; la más perfecta igualdad y uniformidad sigue el contrato; si bien sería de notarse que entre las causales de desahucio por parte del amo respecto de su criado (art. 1.993 inc. $3^{\circ}$ ) se estampa una que dice que el primero tendrá derecho para poner término al contrato cuando el sirviente por cualquiera causa se inhabilitare para el servicio por más de una semana. Causal es ésta que no tiene base alguna en la moral, sobre todo si se toman en cuenta las condiciones de intimidad, confianza y afecto bajo los cuales los criados desempeñan sus servicios. No puede negarse que tal disposición es inhumana” (ibid.).

${ }^{30}$ Real Academia Española, Diccionario de la lengua castellana (10 ed., Madrid, Imprenta Nacional, 1852).

${ }^{31}$ Se sabe que Andrés Bello utilizaba profusamente los diccionarios, y de ello existe huella en toda su obra [PÉREz, Francisco Javier, El diccionario y los diccionarios en la obra de Andrés Bello. Teoría, crítica y elaboración lexicográficas, en Boletín de Filología, 49/1 (2014), p. 128]; y, de hecho, entre los más de cuarenta diccionarios que tenía, se cuentan la cuarta y la décima edición del Diccionario de la lengua castellana compuesto por la Real Academia Española, de 1803 y de 1852, respectivamente (ibid., p. 124).

${ }^{32}$ Sobre ello, véase Martín CaSARES, Aurelia, Domestic Service in Spain. Legislation, Gender and Social Practice, en Fauve-Chamoux, Antoinette (ed.), Domestic Service and the formation of 
domésticos ${ }^{33}$, situación que recién comenzó a cambiar en la segunda mitad del siglo XIX ${ }^{34}$; aspectos que sobre los que aquí, como se ha indicado al comienzo del trabajo, no podemos ahondar.

\section{El CONTENIDO DE LAS REgLAS. ENUNCIACIÓN Y ANÁLISIS DE CONCORDANCIA entre el texto del Código de Bello y los diferentes Proyectos}

\section{Las reglas del Código de Bello. Concordancias con los Proyectos de Código Civil}

El párrafo "Del arrendamiento de criados domésticos" se componía, originalmente, de nueve artículos. A fin de facilitar el análisis que se realiza en el trabajo,

European Identity. Understanding the Globalization of Domestic Work, 16th-21st Centuries (Bern, Peter Lang, 2004), pp. 193-194.

33 "Como es sabido, el servicio doméstico fue el sector que empleó a lo largo de la mayor parte del siglo XIX el grupo más números de trabajadores manuales urbanos. La inmensa mayoría de los sirvientes, cocineros y nodrizas eran mujeres y niños. Durante mucho tiempo, contrariamente a lo dispuesto en los códigos legales, los sirvientes no fueron asalariados, sino casi siempre personas que desarrollaban un trabajo compulsivo no remunerado, o retribuido muy parcialmente en dinero. La causa principal de esta relación servil o semiservil radicaba tanto en la forma de enganche del personal doméstico en su origen, y en la complicidad explícita o subrepticia que manifestaban las autoridades chilenas hacia los sectores acomodados de la sociedad que se procuraban criados, en abierta oposición a los principios proclamados en la constitución [...] Diversas fueron las fuentes del reclutamiento de sirvientes. Una de las más comunes durante las primeras décadas del siglo fue la captura de niños indígenas de ambos sexos (las chinas y los indiecitos) en la frontera sur, y su venta a las familias adineradas de otras regiones [...] También engrosaban las filas del servicio doméstico algunos prisioneros realistas [...], y numerosos indígenas, cautivos de la guerra no declarada que desde muy temprano iniciaron los gobiernos republicanos en contra de la Araucanía [...] Otros domésticos habían sido vendidos por sus propios padres, campesinos pobres incapaces de asegurar su sustento, que se conformaban con recibir algo de dinero y la promesa (verbal) de sus hijos serían tratados con suavidad por los compradores. Este comercio, en un país que había abolido la esclavitud, no tenía, naturalmente, ningún valor legal. Pero ello no impedía que esta práctica, al igual que la anterior, fuera corriente [...] Durante el período inmediatamente posterior a la independencia, una parte importante de los criados eran los antiguos esclavos que seguían sirviendo en las casas de quienes habían sido sus amos [Grez Toso, Sergio, De la "Regeneración del Pueblo" a la huelga general. Génesis y evolución histórica del movimiento popular en Chile (1810-1890) (Santiago, Ril Editores, 2007), pp. 150-154.

${ }^{34}$ En este sentido, como explica ROMERo "la relación entre patrones y sirvientes fue cambiando realmente en la segunda mitad del siglo, como ocurrió en general con todas las relaciones laborales. En las familias había cada vez menos niños dados para criar, o huérfanos de la Providencia, o chinitos de alfombra; los desahucios bruscos eran frecuentes, así como esa forma lateral de conflicto que eran los hurtos. Los criados circulaban casi tan fluidamente como los cocheros, aunque por otra parte seguía siendo común recurrir a mujeres provenientes del fundo familiar o sus vecindades. [ROMERo, Luis Alberto, ¿Qué hacer con los pobres? Elites y sectores populares en Santiago de Chile 1840-1895 (Santiago, Ariadna Ediciones, 2007), pp. 230-231]. En el mismo sentido, Grez Toso: "Hacia mediados de siglo esta situación empezó a modificarse: las formas tradicionales (coactivas) de reclutamiento de personal doméstico y la relación paternalista se resquebrajaron paulatinamente. En vez de niños entregados a familias acomodadas tendió a generalizarse la oferta espontánea de la mano de obra. En lugar de la dependencia vitalicia del criado frente al amo, se hizo cada vez más frecuente la circulación generalizada de sirvientes (cambios repentinos y reiterados de empleo)" [cit. (n. 33), p. 154]. 
y dado que buena parte de los artículos están derogados, se reproduce, en primer lugar, el contenido de los artículos 1987 a 1995 del Código Civil, señalando, en su caso y entre corchetes, las correspondencias de esas reglas con las contenidas en los distintos proyectos de Código Pivil, desde el más reciente al más antiguo, esto es, el denominado Proyecto Inédito, el Proyecto de 1853, el Proyecto de 1946-1947, y el Proyecto de 1942-1945; sólo con indicación del número de los artículos ${ }^{35}$.

Art. 1987: "En el arrendamiento de criados domésticos una de las partes promete prestar a la otra, mediante un salario, cierto servicio, determinado por el contrato o por la costumbre del pais”. [art. 2168 Proyecto Inédito (idéntico); art. 2168 Proyecto 1853; art. 447 Proyecto 1946-1947; art. 43 Proyecto 1942-1945];

Art. 1988. "[inc. $1^{\circ}$ ] El servicio de criados domésticos puede contratarse por tiempo determinado; pero no podrá estipularse que durará más de un año, a menos que conste en la estipulación por escrito; $i$ ni aun con este requisito será obligado el criado a permanecer en el servicio por más de cinco años contados desde la fecha de la escritura. [inc. $2^{\circ}$ ] La escritura podrá renovarse indefinidamente. [inc. 30] El tiempo se entenderá forzoso para ambas partes a menos de estipulación contraria”. [art. 2169 Proyecto Inédito (idéntico); art. 2169 Proyecto 1853; art. 448 inc. 1º Proyecto 1946-1947; art. 44 Proyecto 1942-1945];

Art. 1989. "[inc.1] Si no se ha determinado tiempo, podrá cesar el servicio a voluntad de cualquiera de las partes. [inc. $2^{\circ}$ ] Con todo, si el criado no pudiera retirarse inopinadamente sin grave incomodidad o perjuicio del amo, será obligado a permanecer en el servicio el tiempo necesario para que pueda ser reemplazado, aunque no se haya estipulado desahucio. [inc. $3^{\circ}$ ] El criado que sin causa grave contraviniere a esta estipulación, pagará al amo una cantidad equivalente al salario de dos semanas". [art. 2170 Proyecto Inédito; art. 2171 Proyecto 1853 (sólo la primera parte de la regla); art. 448 Proyecto 1946-1947; sin correspondencia en el Proyecto 1942-1945];

Art. 1990. "La mujer que se contrata como nodriza, será forzosamente obligada a permanecer en el servicio mientras dure la lactancia, o no pueda ser reemplazada sin perjuicio de la salud del niño". [art. 2170 inc. $3^{\circ}$ Proyecto Inédito (idéntico); art. 2175 Proyecto 1853 (sin correspondencia exacta; hay una referencia genérica a los servicios que no pueden suspenderse, y se pone, como ejemplo, el de la nodriza); igual en art. 488 inc. $3^{\circ}$ Proyecto 1946-1947; sin correspondencia en el Proyecto 1942-1945 (en el art. 46 se contempla el supuesto general de un criado contratado para un servicio especial, sin referencia específica a la nodriza)].

Art. 1991. "[inc. $1^{\circ}$ ] Si el criado contratado por cierto tiempo, se retirare sin

\footnotetext{
${ }^{35}$ Para el texto de los Proyectos de Código Civil, véase Bello, Andrés, Obras completas. Vol. XI: Proyectos de Código Civil (Santiago, Pedro G. Ramírez, 1887); Bello, Andrés, Obras completas. Vol. XII: Proyectos de Código Civil (1853), (Santiago, Pedro G. Ramírez, 1888); y Bello, Andrés, Obras completas. Vol. XIII: Proyecto Inédito de Código Civil (Santiago, Pedro G. Ramírez, 1890). En el Proyecto de Código Civil 1942-1945 (De los contratos y obligaciones convencionales), se trata el contrato de arrendamiento (también llamado locación-conducción), en el título XXV. El párrafo 6 de este título se denomina "Del alquiler de obra o servicios, i primeramente del alquiler de dependientes, criados y obreros"; y curiosamente, en el original, este párrafo tiene dos redacciones; la segunda es idéntica a la del Proyecto 1846-1847.
} 
causa grave antes de cumplirlo, pagará al amo, por vía de indemnización, una cantidad equivalente al salario de un mes. [inc. 2०] El amo que en un caso análogo despidiere al criado, será obligado a pagarle por vía de indemnización igual suma, además de la que corresponda al servicio prestado. [inc. $3^{\circ}$ ] Si falta menos de un mes para cumplirse el tiempo estipulado, se reducirá la pena por una y otra parte a lo que valga el salario de la mitad del tiempo que falte". [art. 2172 Proyecto Inédito; art. 2172 Proyecto 1853; art. 44 inc. 3o Proyecto 1946-1947; sin correspondencia en el Proyecto 1842-1845];

Art. 1992. "Si se hubiere estipulado que para hacer cesar el servicio sea necesario que el uno desahucie al otro, el que contraviniere a ello sin causa grave, será obligado a pagar al otro una cantidad equivalente al salario del tiempo del desahucio o de los dias que faltan para cumplirlo" [art. 2176 Proyecto Inédito (idéntico); art. 2174 Proyecto 1853; art. 448 inc. $3^{\circ}$ Proyecto 1846-1847; sin correspondencia Proyecto 1841-1845].

Art. 1993. "[inc. 10] Será causa grave respecto del amo la ineptitud del criado, todo acto de infidelidad o insubordinación, $i$ todo vicio habitual que perjudique al servicio o turbe el orden doméstico; $i$ respecto del criado el mal tratamiento del amo, $i$ cualquier conato de éste o de sus familiares o huéspedes para inducirle a un acto criminal o inmoral. [inc. 2०] Toda enfermedad contagiosa del uno dará derecho al otro para poner fin al contrato. [inc. $3^{\circ}$ ] Tendrá igual derecho el amo si el criado por cualquiera causa se inhabilitare para el servicio por más de una semana". [art. 2176 Proyecto Inédito; art. 2176 Proyecto 1853; art. 448 Proyecto 1946-1947; art. 45 Proyecto 1941-1945].

Art. 1994. "Falleciendo el amo se entenderá subsistir el contrato con los herederos, y no podrán éstos hacerlo cesar sino como hubiera podido el difunto". [art. 2176 Proyecto Inédito; sin correspondencia en los demás].

Art. 1995. "La persona a quien se presta el servicio será creida sobre su palabra, (sin perjuicio de prueba en contrario): 1. En orden a la cuantía del salario. 2. En orden al pago del salario del mes vencido. 3. En orden a lo que diga haber dado a cuenta por el mes corriente [art. 2177 Proyecto Inédito; art. 2177 Proyecto 1853; sin correspondencia en los demás].

\section{Algunas apreciaciones generales sobre el contenido de la regulación}

El análisis sobre el contenido de la regulación del Código de Bello, y el de los textos de los Proyectos de Código Civil, permite realizar algunas apreciaciones generales. La primera, es que la regulación contenida en los artículos 1987 a 1995 del Código de Bello pone especial énfasis en la terminación del contrato y sus consecuencias, sobre la base de la determinación del plazo (fijo o indefinido) y la causa de la terminación. En efecto, siete de las nueve reglas tratan de ello (artículos 1988 a 1994 CC). Esta es claramente la principal preocupación del legislador.

Por otro lado, se observa que esta regulación no termina de desprenderse de los rasgos que tradicionalmente habían caracterizado la relación entre amos y criados en Chile: una relación que, como sugiere Alejandra Araya, encierra la idea de un pacto, en el que el poderoso, en cumplimiento de una especie de deber moral, y en un sentido paternalista, ofrece protección al débil, quien la acepta a 
cambio de sus servicios y su subordinación ${ }^{36}$. Prueba de ello es, por ejemplo, el hecho de que el criado, si bien puede renunciar, no pueda hacerlo si ello supone "una grave incomodidad o perjuicio del amo" (art. 1989 CC); o que se considere como una causa grave para despedirle antes del tiempo su "infidelidad o insubordinación" (art. 1993 CC); o el que, en relación con ciertos hechos (como el pago del salario), se crea al amo (art. 1995 CC). Con todo, la regulación no está del todo anclada en el pasado, pues supone la libertad e igualdad de las partes para celebrar el contrato, acordar su objeto y duración (estableciendo plazos máximos), y asegura el derecho de las partes a ponerle término. Por eso, es posible afirmar que la regulación se hace cargo "de una relación contractual basada en el salario, reflejando en sus disposiciones la gran mutación que estaba llevando a la sociedad chilena a transitar desde un modo de producción, una cultura y un sistema de relaciones sociales de tipo colonial a uno de carácter decididamente capitalista" ${ }^{37}$.

Finalmente, como observación general sobre la regulación, el ejercicio de concordancia entre las normas y el texto de los proyectos permite observar una evolución, desde el primer proyecto hasta el texto definitivo; a partir de un n ú c l e o i n i c i a l, que lo constituyen estas reglas: 1) el contrato puede contratarse a plazo fijo o a plazo indefinido; 2) el contrato de plazo fijo tiene una duración máxima establecida en la ley; 3) en el contrato de plazo fijo es posible la terminación anticipada y unilateral, en ciertos casos (motivos graves); y 4) el criado no puede abandonar el servicio si ello implica inconveniente para el amo. Ese núcleo inicial se va desarrollando, en nuevas reglas (que explicitan o constituyen derivaciones de las anteriores), sin perjuicio de introducirse algunas reglas nuevas. Sobre esta evolución, conviene apuntar:

i. Si bien la regulación del Código de Bello es p ráctic a me n te idént i c a a la que contenía el denominado Proyecto Inédito, existe entre ambos una diferencia muy importante: hasta el Proyecto Inédito inclusive, la regulación del párrafo que analizamos no está dirigida únicamente a los arrendamientos de criados domésticos, sino que también se refiere a otros sujetos que realizan servicios personales ("dependientes", "obreros", “artesanos").

36 "La idea de contrato salarial entre personas libres cuyo bien de intercambio es el trabajo y el precio justo por él no predomina en el siglo XVIII ni en la primera mitad del siglo XIX. Los sirvientes, en tanto esclavos o descendientes de ellos, indios encomendados, depositados, alquilados o libres concertados a servir, mujeres $d$ e b a j a e s f e r a, niños y niñas criados dentro de una familia, depositados o e m p en a d o s, peones e inquilinos y aprendices de artesanos, convivieron y compartieron los espacios domésticos de sus patrones bajo la noción de pacto en el que un poderoso, que lo era por tener capacidad de proteger a otro, extendía su manto benefactor -alimento, vestuario, techo, educación-a un pobre desvalido. Éste, al aceptar esa protección, aceptaba la subordinación, pero capitalizaba a su favor el pacto como promesa de que, en caso de incumplimiento, podría cobrar como palabra de honor empeñada [...] Era un mundo en el que los poderosos debían proteger a los desvalidos en un sentido paternal. Se debía devolver esa protección con servicios de todo tipo, pero también con símbolos que hacían concreto el poder: respeto, fidelidad; obediencia, sumisión y agradecimiento", [ARAYA, Alejandra, Sirvientes contra amos: las heridas en lo intimo propio, en GAZMURI, Cristián; SAGREDO, Rafael (eds.), Historia de la vida privada en Chile (Santiago, Ed. Taurus, 2005), I, pp. 161-162.

${ }^{37}$ Grez Toso, Sergio, cit. (n. 33), p. 154. 
ii. Aunque existe una concordancia general entre el contenido del Proyecto Inédito y el Proyecto de 1853, se observan algunas diferencias sustantivas que vale la pena destacar. Primero, en la definición del contrato se introduce la expresión "o por la costumbre del país" (como forma determinar el contenido del servicio). Segundo, se señala expresamente que el contrato a plazo puede re novarse e x p r e s a m e n t e. Tercero, aparece formulada de manera autónoma la norma referida a la nodriza. Cuarto, se introduce por primera vez la regla según la cual el contrato no termina por la muerte del amo.

iii. El Proyecto 1853 introduce la regla por la cual ha de creerse al amo, que contiene el actual artículo $1995 \mathrm{CC}$, inexistente en los proyectos anteriores.

iv. Existe una importante similitud entre el Proyecto 1946-1947 y el Proyecto 1941-1945, siendo el único punto relevante de diferencia entre ambos la formulación expresa de la regla que establece el derecho de cualquiera de las partes a poner término al contrato en caso de que el contrato sea de plazo indefinido.

Como se ha indicado al comienzo, el ejercicio realizado aquí es un punto de partida necesario para poder identificar correctamente las fuentes normativodogmáticas de cada una de estas reglas; cuestión que se desarrolla en los dos apartados que siguen, comenzando por el estudio de las propias notas de Bello, y siguiendo con el análisis de las fuentes normativo-dogmáticas del Código Civil en materia de obligaciones y contratos, a las que el propio Mensaje se refiere.

\section{LAS NOTAS DE BELLO A PROPÓSITO DEL ARRENDAMIENTO DE CRIADOS} DOMÉSTICOS

El único de los textos de los proyectos que contiene notas de Bello es el Proyecto de $1853^{38}$. En él, a propósito de la regulación de los criados domésticos, sólo existe una nota, que está referida al artículo 2177 del Proyecto 1853, que corresponde al actual artículo 1995 del Código Civil. Esta regla, que tiene idéntica redacción en ambos textos, se introdujo precisamente en el Proyecto 1853. La referencia anotada por Bello es, textualmente, la siguiente: "Art. 2177 núm 3. C. F., 1781". Ello podría tomarse como indicación de que el número 3 del artículo 2177 del Proyecto 1853 tiene por fuente normativa el artículo 1781 Code Civil de 1804. Sin embargo, sabemos que ha de procederse con cautela antes de arribar a tal conclusión, pues, como afirma Guzmán Brito, "es imposible reconocer la existencia de un criterio único aplicado por Bello a sus notas; por lo demás, el mismo lo reconoció [...] al hablar [...] de la ausencia de un «método uniforme»; y en consecuencia es sólo con precauciones y teniendo presente las advertencias

${ }^{38}$ Si bien la versión de Amunátegui del Proyecto inédito sí tiene notas, ellas, como afirma Guzmán, "no pertenecen a los originales de dicho proyecto, sino que provienen de apuntes personales de Bello, que Amunátegui incorporó en los artículos a que más les convenían, según su parecer" [GuZmán Brito, Alejandro, Andrés Bello codificador. Historia de la fijación y codificación del derecho civil en Chile (Santiago, Ediciones de la Universidad de Chile, 1982), I, p. 408]. Sobre las notas de Bello, véase, además, Amunátegui Reyes, Miguel Luis, Andrés Bello y el Código Civil (Santiago, Imprenta Cervantes, 1883), pp. 131-137 y ss. 
del propio Bello que debe procederse a la utilización de estas notas" ${ }^{39}$. Las notas de Bello, pues, podrían referir a la fuente, pero también podrían indicar simplemente concordancias o similitudes. Creo, sin embargo, que en este caso resulta razonable sugerir que la nota de Bello al artículo 2177 Proyecto 1853 sí es indicativa de su fuente; el tenor literal del artículo 1781 Code así lo sugiere: "Le maitre est cru sur son affirmation; [inc. $1^{\circ}$ ] Pour la quotité des gages; [inc. $2^{\circ}$ ] Pour le paiement du salarie de l'année échué; [inc. $3^{\circ}$ ] Et pour les à-comptes donnés por l'année courante".

Con todo, conviene realizar algunos comentarios sobre la adopción del artículo 1781 Code en el 1995 CC. Un primer comentario es que, pese al tenor de la nota de Bello, es todo el texto del artículo 2177 del Proyecto 1853 el que parece tomado del artículo 1781 Code, y no sólo su numeral tercero. En efecto, y como se puede observar, el artículo chileno reproduce el encabezado y los tres numerales de su par francés, aunque lo hace sustituyendo las referencias a la anualidad, como medida de tiempo de los incisos $2^{\circ}$ y $3^{\circ}$ ("l'année échué"; "l'année courante"), por referencias al mes ("mes corriente"; "mes vencido").

Por otro lado, como se ha indicado al comienzo del trabajo, esta regla ha sido especialmente utilizada por la doctrina más moderna como prueba del carácter discriminador de la regulación, en cuanto favorece al amo sobre el criado (porque se le cree al primero), aunque ello se sostiene sin ahondar en su fundamento o contexto histórico. Sobre este punto, conviene destacar que al introducir esta regla en el Code Civil se recogió un uso consagrado por la jurisprudencia del Antiguo Régimen ${ }^{40}$. Se trata de una regla que, señala Duranton, obedece a ciertos "motifs de convenance faciles à sentir "'̌1 . ¿Cuáles son esos motivos? Por un lado, la regla se justificó por la dificultad de la prueba documental, dado que estos contratos no solían constar por escrito; y por las dificultades que hubiera supuesto admitir la prueba testimonial, no sólo porque implicaría la posibilidad de una infinidad de juicios, sino que posiblemente, implicaría muchos fraudes, por el riesgo de que los criados u obreros presentaran testigos concertados ${ }^{42}$; siendo razonable que la ley, entonces, haga fe-como presunción simplemente legal- de lo que diga una de las partes. ¿a cuál? Troplong se lo pregunta, retóricamente, así: "entre el criado y el amo, quién es el que, por su educación, costumbres y posición social, es el más digno de fe? El amo”³. Desde otro punto de vista, Delvincourt entiende asumiendo que la regla aplica cuando no existe prueba escrita- que es justificado que sea creído el amo, pues él tiene la calidad de deudor de esas sumas ${ }^{44}$. Si bien Delvincourt no desarrolla el punto, su explicación ha de relacionarse con las reglas

\footnotetext{
${ }^{39}$ GuZmán Brito, Andrés Bello, cit. (n. 38), p. 409.

${ }^{40}$ Duvergier, Jean-Baptiste, Le droit civil français suivant l'ordre du Code. Continuation de Toullier (5a ed., Paris, 1838), p. 345.

${ }^{41}$ Duranton, Alexandre, Cours de droit civil suivant le code français ${ }^{4}$ (Bruxelles, 1841), XVII, p. 237.

${ }^{42}$ Ibid., p. 237 ; en el mismo sentido, Troplong, Raymond Théodore, Le droit civil expliqué suivant l'ordre des articles du Code: De l'échange et du Louage (Bruxelles, 1841), p. 250.

43 " ¿Entre le locateur de services et le maître, quel est celui qui par son éducation, ses habitudes, sa position social, est le plus digne de foi ? C'est le maître" [TROPLONG, Raymond Théodore, cit. (n. 42), p. 250].

44 "S'ily a contestation sur la quotité de gages convenus, ou de ceux qui sont encores dus, le maître,
} 
generales sobre prueba de las obligaciones que contenía el Code Civil, que ponían de cargo de quien alegaba la existencia de la obligación, probarla: y en este caso, sería el criado, pues es él quien reclama que se le debe (y el monto) ${ }^{45}$. En todo caso, conviene tener presente que las críticas que en Francia recibió este artículo, por suponer una suerte de superioridad moral del amo respecto del criado, llevaron, primero, a que la jurisprudencia procurara delimitar su alcance, y luego, a su derogación en el año $1868^{46}$. Las indicadas razones de la regla del artículo 1781 Code, parecen perfectamente extrapolables, considerando la realidad social de Chile y las reglas del Código Civil chileno sobre la prueba de las obligaciones.

Finalmente, como último comentario, la adopción en Chile de tal regla extranjera (tomada, como aquí se ha sugerido, del art. 1781 Code Civil) no debió hallar, en todo caso, demasiada resistencia. En la antigua legislación española, hay algunas reglas que establecen que ha de creerse al amo por sobre el criado, si bien no exactamente en los mismos supuestos que trata el artículo 1995 CC. Por ejemplo, en la Novísima Recopilación, un texto ampliamente utilizado ${ }^{47}$, se contiene una le y por la cual se establece, en síntesis, que el criado que renuncia al servicio de un señor no puede trabajar para otro señor en el mismo lugar; salvo que hubiese sido despedido, indicándose que, en caso de duda sobre si el criado renunció o fue despedido, se estará a lo que diga el amo de la casa de la cual salión ${ }^{48}$. Como se ve, en caso de duda se cree al amo. Esta regla resulta interesante de destacar, además, porque, más allá de las consecuencias que atribuye a la renuncia, se observa que en

comme débiteur, en est cru sur son affirmation" [DELVINCOURT, Claude-Étienne, Cours de Code Napoléon (Paris, 1813), II, p. 189.

${ }^{45}$ Sobre las reglas de la prueba, véase, por ejemplo, DuverGier, Jean-Baptiste, cit. (n. 40) p. 346 y ss.

${ }^{46}$ Sobre la aplicación y posterior derogación de la regla, y en general, para un análisis detallado de su historia, CASTALDO, André, L'histoire juridique de l'article 1781 du Code Civil: "Le maître est cru sur son affirmation", en Revue Historique de Droit Français et Étranger, 55/2 (1977), pp. 211-237. Es interesante apuntar que, el hecho de que la regla se derogara en el año 1868 no fue un impedimento para que el Código Civil español la adoptara, casi treinta años después, en 1889.

${ }^{47}$ Sostiene Guzmán Brito que, dado que no consta que se hubiera concedido un p a s e a la Novísima Recopilación (trámite necesario) "estrictamente hablando, ella no regía en estas provincias"; pero admite, de inmediato, que "de hecho terminó por acaecer lo contrario, pues su invocación y aplicación fue constante, al menos en Chile con posterioridad a la independencia [GuZMÁn Brito, Andrés Bello, cit. (n. 36), p. 47].

${ }^{48}$ Novísima Recopilación, Libro VI (De los vasallos: su distinción de estados y fueros: Obligaciones, cargas y contribuciones), título XVI (De los criados), ley I: "Mandamos, que el criado ó criada, de qualquier condicion ó calidad que sea, en qualquier servicio ó ministerio que sirva, que se despidiere de su señor ó amo, no pueda asentar ni servir á otro señor ni amo en el mismo lugar y sus arrabales, ni otra persona alguna le pueda rescebir ni acoger, sin expresa licencia y consentimiento del señor y amo de quien se despidió ; y que el criado ó criada que lo contrario hiciere, y sin la dicha licencia y expreso consentimiento asentare con otro, esté preso en la cárcel por veinte dias, y sea desterrado por un año del tal lugar; y el que le recibiere en su servicio caya en pena de seis mil maravedis aplicados por tercias partes; pero que si el dicho criado ó criada no se despidiere de su amo ó señor, y fuere por él despedido, pueda asentar y servir á otro en el mismo lugar, conque la persona que le hobiere de rescebir lo haga primero saber al señor ó amo de cuya casa salió, para entender y saber si fué despedido, ó se despidió él, sobre lo qual se esté al dicho y declaracion del señor de cuya casa salió $[\ldots]$..." 
los contratos de los criados domésticos cabe tanto el despido como la renuncia, lo que podría servir de fuente o justificación de las reglas del Código de Bello sobre la materia. En el Fuero Viejo de Castilla ${ }^{49}$ encontramos otro ejemplo, pues hay una regla que sostiene que ha de creerse al amo (no pareciendo sospechoso) si afirma, bajo juramento, que el criado le había llevado algo de su casa cuyo valor no excediese de quince sueldos ${ }^{50}$.

\section{OTRAS FUENTES NORMATIVO-DOGMÁTICAS, EN RELACIÓN CON LA REGULACIÓN DE LAS OBLIGACIONES Y CONTRATOS}

Habiendo identificado la fuente del artículo 1995 CC, y analizado su fundamento, resta, según el plan trazado al comienzo, analizar si es posible identificar las fuentes normativo-dogmáticas de las otras reglas del párrafo dedicado al arrendamiento de criados domésticos. Siguiendo el itinerario que propone el propio Mensaje del Código civil, ello supone analizar: 1) el derecho vigente a la entrada en vigor del Código Civil ("La legislación actual, que es lo más"); 2) la regulación contenidas en otros códigos civiles extranjeros ("la autoridad de un código moderno, en especial el francés" y 3) la literatura jurídica consultada por Bello ("la doctrina de alguno de los más eminentes jurisconsultos").

\section{Legislación vigente antes de la entrada en vigor el Código Civil}

Sabemos que el principal cuerpo normativo en relación con los negocios jurídicos se encuentra en las Partidas ${ }^{51}$. En las Partidas existe un título dedicado al contrato de arrendamiento o locación (Part. 5, 8), pero no existe propiamente

\footnotetext{
${ }^{49}$ Sobre la vigencia del Fuero Viejo de Castilla en Chile, el propio Bello expresa que existen dudas e incertidumbres. En sus palabras: "En cuanto al Fuero Viejo de Castilla, notaremos que la Ley de Toro da el primer lugar en el canon legal a las pragmáticas y ordenamientos de los reyes (comenzando por el de Alcalá) sin necesidad de que se pruebe su uso. Y siendo cierto que el Fuero Viejo, cual hoy lo tenemos, fue compilado por el rey don Pedro, monarca legítimo de Castilla, que sucedió en el reino a don Alfonso el Undécimo, promulgó el Ordenamiento de Alcalá; parece constante que este libro tiene todavía fuerza obligatoria no como quiera, sino independiente de la costumbre, y superior a la de las Siete Partidas. Tal es, en efecto, el modo de pensar de sus últimos editores Asso y Manuel. Otros, con todo sostienen un dictamen diferente, fundándose en que la compilación del rey don Pedro no fue acompañada de ningún decreto real, que mandase guardar sus leyes. Y estando vigentes entre nosotros las leyes castellanas en lo que no han sido derogadas por los estatutos patrios, es visto que en este punto como en otros muchos hemos heredado las incertidumbres y oscuridades de la legislación Española” [BELLO, Andrés, Obras completas. Vol. XVIII. Temas jurídicos y sociales (2a ed., Caracas, Fundación La Casa de Bello, 1981); originalmente publicado en El Araucano (n. 472 y 474, de 13 y 27 de septiembre de 1839)].

50 “[...] si el Señor se querellare de agund mancebo o manceba, que le lieuò alguna cosa de sua casa fasta en quince sueldos, quanto jurare el Señor, devel pechar el mancebo, seyendo el Señor tal ome, que sea sin sospecha a bien vista del judgador, e de omes bonos" [Fuero Viejo de Castilla, Libro 4, título 3].

${ }^{51}$ Bravo Lira, Bernardino, Vigencia de las Partidas en Chile, en Revista de Estudios HistóricoJurídicos, 10 (1985), especialmente, pp. 45 y 93 y ss. Ello es especialmente cierto en materia de arrendamiento; pues, en todas las recopilaciones posteriores, incluida la Novísima Recopilación, no se encuentra ninguna modificación sustancial de la regulación contenida en las Partidas
} 
una regulación del arrendamiento de criados domésticos. En efecto, no hay en dicho título divisiones o apartados, y las reglas o leyes que lo componen se recogen -como ocurre en el Digesto- en forma inorgánica. Con todo, la lectura de las leyes que componen el título dedicado a la locación permite concluir que no hay reglas referidas específicamente al arrendamiento de criados domésticos, siendo las reglas del título 8, en general, relativas al arrendamiento de cosas y a lo que hoy denominaríamos contrato de confección de obra y al transporte ${ }^{52}$.

Es importante tener presente que la figura de los "siervos", a la que se refieren las Partidas en otros Títulos y Libros, no pueden ser consideradas análogas a los "criados domésticos" a los que se refiere el Código Civil; y ello, pese a la similitud que existe entre las voces siervo y sirviente. Los "siervos" a los que se refieren las Partidas son una categoría de personas que corresponde, en realidad, al esclavo, y no refiere al hombre libre que trabaja a cambio de una paga ${ }^{53}$. De hecho, los siervos pueden ser o b j e t o de contrato arrendamiento, y algunas de las reglas se refieren a ellos precisamente de esta manera (Part. 5, 8, 8). Por otro lado, en las propias Partidas aparecen claramente definido qué es un "criado", diferenciado del "siervo" ${ }^{4}$. Como se ha mencionado, en el Código de Bello, el arrendamiento de criados domésticos no supone una sujeción personal, no, al menos, una sujeción distinta de la que supone cualquier contrato por el cual se contrae una obligación de hacer ${ }^{55}$. La relación amo-criado, en cuanto es de origen contractual, supone

[cfr. Solé Resina, Judith, Arrendamiento de obras o servicios (perfil evolutivo y jurisprudencial) (Valencia, Tirant Lo Blanch, 1997), pp. 43-44].

${ }^{52} \mathrm{Y}$ para ello puede ensayarse esta explicación: las Partidas reproducen, básicamente, la regulación del Digesto; que tampoco presta atención al arrendamiento de servicios (locatio conductio operarum) porque este contrato tenía una importancia más bien marginal en Roma: por un lado, porque, sólo pueden ser objeto de arrendamiento los servicios i n f e r i o r e s; y por otro lado, debido a la disponibilidad de esclavos para realizar tales servicios inferiores (y, por realizarlos esclavos, esos servicios se realizan fuera del marco de una relación contractual) [cfr. Rodríguez EnNES, Luis, El singular renacimiento de la autonomía de la voluntad y la "locatio conductio operarum et operis" como consecuencia de la presente depresión económica, en Revista de Derecho de la Pontificia Universidad Católica de Valparaiso, 32 (2009), pp. 188-190; y Zimmermann, Reinhard, The Law of Obligations. Roman foundations of the civilian tradition (1990, reimp. Cape Town, Juta and Co., 1992), p. 387. La estructura productiva y social en tiempo de las Partidas, no es muy diferente a la romana.

${ }^{53}$ De hecho, en las Partidas, se señala que "El estado de los homes et la condición dellos se departe en tres maneras; ca ó son libres, ó siervos ó aforrados, á que se llaman en latin libertos [...]" (Part. 4, 23).

54 "Part. 4, 20, 2: "Criado tomó este nombre de una palabra que dicen el latín creare, que quiere tanto decir como criar et enderezar la cosa pequela, de manera que venga a tal estado porque pueda guarecer por si. Et segunt dixieron los sabios antiguos departimiento ha entre nudrimiento et crianza; ca crianza es quando alguno face pensar de otri que cria dandol de lo suyo todas las cosas quel fueren meester para vevir, teniendol en su casa et en su compaña: et nudrimiento es encelamiento que facen los ayos a los que tiene en su guarda, e los maestros a los discipulos a quien muestran su esciencia o su menester, enseñandoles buenas maneras et castingandolos de los yerros que facen [...]".

${ }^{55}$ Considérese, al respecto, que el artículo 1553 del Código Civil chileno admitió, en caso de incumplimiento de una obligación de hacer cualquiera (con independencia de la fuente), que el acreedor pueda solicitar, entre otras cosas, "que se apremie al deudor para la ejecución del hecho convenido"; apremio que puede consistir en multa y arresto. 
la libertad de ambas partes para entrar en ella, y el contenido de la regulación, como ya se ha puesto de relieve, asegura, en términos generales, el derecho de las partes a poder salir de esa relación (y, además, bajo condiciones relativamente simétricas). El "criado" del Código de Bello, no puede, por tanto, asimilarse al "siervo" de las Partidas.

Dado ese enfoque de la regulación de las Partidas, no parece que sea posible considerar a este texto como una fuente normativa relevante de la regulación de los criados domésticos del Código Civil. Con todo, creo que sí ha de reconocerse su influencia en relación con una regla particular, que, como se verá, no está recogida en otras fuentes que se analizan luego. Me refiero a la regla del artículo 1994 CC ("Falleciendo el amo se entenderá subsistir el contrato con los herederos, y no podrán éstos hacerlo cesar sino como hubiera podido el difunto"), regla que se encuentra en Part. 5, 8, 2, aunque referida, como se ha dicho, a toda clase de arrendamiento, y con una diferencia: ni la muerte del arrendador ni la del arrendatario pone fin al contrato: "[...] Et si por ventura logase alguno casa o otra cosa a tiempo cierto, et se moriese enante que el tiempo se compliese, su heredero se debe servir et aprovechar de la cosa logada hasta que se cumpla el tiempo, et es tenudo de pagar por ella lo que debie dar el finado que la habie logada. Otrosi decimos que si se moriese el señor de la cosa logada, que su heredero es tenudo de guardar el pleyto, segunt que lo puso el finado et de lo haber por firme [...]". Esta regla que establece la transmisibilidad del contrato de arrendamiento proviene del derecho romano ${ }^{56}$; y de hecho, así la recoge Bello en sus Instituciones ${ }^{57}$, y en el propio Código Civil para el arrendamiento de cosas (en cuanto no enuncia, entre las causas de terminación, la muerte de alguna de las partes; cfr. art. 1950 CC). Sin embargo, hay que tener presente que la doctrina romanista entiende que la locatio conductio, cuando recae en servicios personales (operarum) y en el caso de la confección de obra (operis) sí termina por muerte, pero sólo por la muerte de quien presta los servicios ${ }^{58}$. De ahí, entonces, la necesidad de especificar que la muerte de la persona a quien se prestan los servicios no pone fin al contrato ${ }^{59}$.

Fuera de las Partidas, y como ya se ha indicado, en la Novísima Recopilación

\footnotetext{
${ }^{56}$ En efecto, en las fuentes es claro que el principio es la transmisibilidad ["Muerto el arrendatario durante el tiempo del arrendamiento, le sucede en él con el mismo título su heredero" (Inst. 3, 24, 6); "Desconoces el camino de la verdad, estimando que los herederos del arrendatario no suceden en los arrendamientos, porque, si el arrendamiento es perpetuo, se transmite también a los herederos, y si temporal, durante el tiempo de la locación le incumbe también al heredero la carga del contrato" (Cód. 4, 65, 109)].

${ }^{57} \mathrm{Al}$ respecto, Bello consigna expresamente "Muertos el locador o conductor subsiste la locación, y suceden en sus derechos y obligaciones sus herederos" [BeLLo, Obras completas. Vol. XVII. Bello, p. 155].

${ }^{58}$ cfr. SeVErin Fuster, Gonzalo, Sobre, cit. (n. 19) p. 381, nota 69; con indicación de los autores que así lo sostienen, y las reglas de otros contratos intuito personae, de las que se deduciría el principio.

${ }^{59}$ También se recoge esta regla, en el Código Civil, en relación con el arrendamiento de confección de obra, en el artículo 2205 CC: [inc. $1^{\circ}$ ] "Todos los contratos para la construcción de una obra se resuelven por la muerte del artifice o del empresario [...] [inc. $2^{\circ}$ ] Por la muerte del que encargó la obra no se resuelve el contrato".
} 
encontramos una regla de la que se sigue que era admitido que el criado doméstico fuera despedido, y que podía renunciar (Libro VI, tít. XVI, ley 1; supra, nota 48); regla que bien podría explicar la contenida en el inciso primero del artículo 1989 CC, que precisamente, permitía a ambas partes poner término al contrato. La regla, descansa, en todo caso, en la comprensión del propio Bello sobre la naturaleza del servicio doméstico (como lo demuestra su opinión expresada en un artículo de su autoría sobre la locación de servicios $)^{60}$; sin perjuicio de que, en la formulación de las reglas, pueda reconocerse, al menos parcialmente, cierta influencia de alguno de los códigos civiles extranjeros, tal como se muestra a continuación.

\section{Códigos extranjeros}

\section{a) el Código Civil francés}

Como se ha recordado, el Mensaje, junto con las Partidas, refiere especialmente al Código Civil francés como fuente principal en materia de obligaciones y contratos. Y, como sostiene Guzmán, "sin duda fue el cuerpo legal extranjero más influyente en el Código Civil" "1. Ya se ha mostrado la influencia directa del artículo 1781 Code en el actual 1995 CC. ¿Qué ocurre con el resto de las reglas? El respectivo párrafo del Code Civil sobre el arrendamiento de criados domésticos y obreros sólo contenía dos artículos. El otro, el artículo 1780 Code, establece: “On ne peut engagerses services qu'à temps, ou pour une entreprise déterminée”. El artículo 1780 Code está redactado en términos negativos: no pueden contratarse los servicios sino por un tiempo (tiempo que no específica ni limita) o para una obra determinada. El Código de Bello no recoge esa formulación, sino otra, muy distinta, que resulta de la lectura de dos artículos: el artículo 1988 CC, que establece que el contrato puede celebrarse "por tiempo determinado"; y el artículo 1989 CC, que admite la contratación de plazo indefinido ("si no se ha determinado tiempo"). Con todo, es posible afirmar la regla implícita o subyacente en ambos códigos es la misma: no pueden contratarse los servicios a perpetuidad o por toda la vida del criado, aun cuando ninguno de los códigos ello se señale expresamente. En el caso del Código francés, los comentaristas del Code pronto precisaron que no cabía el contrato "por toda su vida"; porque ello sería contrario a la libertad ${ }^{62}$. En el Código de Bello, tal problema no se plantea, pues el artículo 1988 CC establece directamente los plazos máximos admitidos: un

\footnotetext{
${ }^{60}$ Véase el ya referido texto de Bello La locación de servicios y el mandato [cit. (n. 26)].

${ }^{61}$ Guzmán Brito, Andrés Bello, cit. (n. 36), p. 422.

${ }^{62}$ En este sentido, Delvincourt, por ejemplo, afirma: "non pas cependant que l'on puisse stipuler que le bail durera pendant toute la vie du domestique ou de l'ouvrier; une pareille stipulation seroit nulle, comme contraire à la liberté" [DeLvincourT, Claude-Étienne, cit. (n. 44), p. 189]. En idénticos términos, Rogron, Joseph-André, Codes français expliqués, par leurs motifs, par des exemples, et par la jurisprudence, suivis des formulaires (Paris, 1836), p. 311. La aclaración de los comentaristas es necesaria, pues, el tenor literal del artículo 1780 Code, al menos, admite tal forma de contratación, pues "toda la vida" de una persona es, precisamente, un plazo. De hecho, esa misma razón -la afectación de la libertad personal- fue esgrimida, en la discusión del Code Civil, para explicar que si el contrato de doméstico se hubiera celebrado con un plazo fijo, no es posible obligar al criado a permanecer en la casa del amo hasta cumplir el término convenido, y que en tal caso, ha de ser condenado a indemnizar los perjuicios que resulten del
} 
año, si el contrato no consta por escrito, y cinco años, si consta por escrito (sin perjuicio de que pueda renovarse el contrato de común acuerdo). Por lo dicho, no creo que pueda admitirse influencia alguna al artículo 1780 Code, sobre los artículos 1988 y 1989 CC. Simplemente, la solución de ambos códigos obedece a un mismo principio; $y$, en este sentido, la justificación de la regla subyacente del Código de Bello, en cuanto impide la contratación de criados a perpetuidad, debe entenderse, principalmente, porque ello implicaría una forma de esclavitud, estado que ya había sido abolido en Chile cuando Bello comienza a trabajar en la codificación civil. En este sentido, podría sugerirse, además, cierta influencia de Bentham, para quien la perpetuidad del servicio es el único criterio que permite propiamente distinguir al esclavo del criado doméstico libre ${ }^{63}$, explicación que, sin duda, Bello conocía bien ${ }^{64}$. Bentham, además, sostiene que "si se prescinde de la cuestión de la esclavitud, no hay mucho que decir sobre el estado de señor y sus estados correlativos, constituidos por las diversas especies que hay de servidores: a las partes interesadas toca el arreglarse como les convenga" ${ }^{65}$; una idea que parece reflejarse, en parte, en definición del contrato de arrendamiento de servicios de criados domésticos del artículo 1987 CC, que no define qué es, o que hace típicamente, un criado doméstico, sino que entrega, en primer lugar, al propio contrato, la determinación del contenido de los servicios.

\section{b) otros códigos}

Establecida, pues, la limitada influencia que puede reconocerse al Code Civil de 1804, conviene considerar la posible influencia de otros códigos extranjeros. Sobre este punto, siguiendo a Guzmán Brito, hay que considerar que Bello utiliza, como materiales, una gran cantidad de códigos extranjeros, pero que lo hace en todo caso, de manera más bien esporádica, siendo, entre los más recurridos por Bello, el Código Civil austriaco (ABGB) de 1811; el Código de Louisiana de 1825; y el Proyecto de Código Civil de Goyena, de 1851 (que Guzmán incluye en este grupo, pese a que no se trata propiamente de un Código en vigor $)^{66}$.

Podemos, desde ya, descartar la posible influencia del ABGB de 1811, pues éste, si bien contiene un capítulo dedicado a los contratos de servicios, no existe un

incumplimiento de su promesa [ $c f r$. De MaleVIlle, Jacques, Analyse raisonée de la discusión du Code Civil au conseil d'etat (Paris, 1822), III, pp. 401-402].

${ }^{63}$ Bentham trata el punto en sus Principios de legislación, Parte tercera ("Derechos y obligaciones que deben aplicarse a los diferentes estados privados"; en el Capítulo 1 ("Señor y servidor") [cfr. Bentham, Jeremías, Tratado de legislación civil y penal (Paris, 1838, trad. Ramón Salas), p. 137 y ss.].

${ }^{64}$ Sobre la influencia de Bentham en Bello, y especialmente, sobre el conocimiento de Bello de los Principios de legislación de Bentham, véase, JAKSIC, Iván, cit. (n. 17), pp. 74 y ss.; 210 ; y GuZmán Brito, Andrés Bello, cit. (n. 36), pp. 257-258. El estudio de los Principios de legislación de Bentham, forma parte de los planes de estudio de distintas propuestas de Bello en materia educativa (cfr. Bello, Andrés, Obras completas. Vol. XXI. Temas educacionales (2a ed., Caracas, Fundación La Casa de Bello, 1981), pp. 200, 205 y 274).

${ }^{65}$ Bentham, Jeremías, cit. (n. 63), p. 137.

${ }^{66}$ GuZmán Brito, Andrés Bello, cit. (n. 36), p. 423. 
párrafo o apartado referido específicamente a los criados domésticos ${ }^{67}$, y la única regla que se refiere específicamente a ellos señala expresamente que los derechos y obligaciones entre amos y criados se contienen en las regulaciones especiales (art. $1172 \mathrm{ABGB}$ de 1811) ${ }^{68}$.

El Código Civil de Lousiana de 1825 (en adelante, CCL), en cambio, sí contiene una sección dedicada específicamente a los criados domésticos y obreros, al interior de un capítulo sobre el arrendamiento de obras y servicios, que reproduce la estructura del Code Civil français ${ }^{69}$. Sin embargo, en relación con el fondo, esta sección no se limita a reproducir los artículos 1780 y 1781 Code, sino que contiene un mayor desarrollo, en cinco artículos (artículos 2717 a 2720 del CCL) ${ }^{70}$. De los artículos 1780 y 1781 del Code, sólo se recoge el primero, en el artículo 2717 CCL. Los otros cuatro artículos que componen esta regulación tratan de la terminación del contrato. El artículo 2718 CCL admite la terminación unilateral y sin expresión de causa, por cualquiera de las partes, y si bien no se dice que ello sólo aplique a los contratos de duración indefinida, se desprende que es así, pues el artículo siguiente, el $2719 \mathrm{CCL}$, establece que no es posible al trabajador renunciar, ni al empleador despedir al trabajador, antes del plazo acordado, sino es por causa grave (por tanto, esta última regla se aplica a los contratos de plazo fijo). Los dos artículos que siguen establecen las consecuencias de la renuncia o el despido sin causa grave. El artículo 2720 CCL establece que el empleador que pone fin al contrato, antes del plazo, debe pagar al trabajador el salario del tiempo por el cual había sido contratado; y el artículo 2721 CCL 1825 establece que si es el trabajador quien renuncia perderá el salario, además de restituir todo

${ }^{67}$ El ABGB reguló, en capítulos separados, el arrendamiento de cosas (Capítulo 25) de los contratos onerosos de servicios (Capítulo 26, que no llama "arrendamiento"; sino "contrato de servicios" ("Von Verträgen uber Dienstleistungen"), compuesto por los artículos 1151 al 1174 ABGB. El examen de las reglas permite concluir que ellas se refieren, en su mayoría, a los contratos para la confección de obra; a los servicios liberales, y al contrato de edición.

${ }^{68}$ Art. 1172 ABGB de 1811 (texto original): "Dienstherren und dem Dienstgesinde sind in den besonderen darüber bestehenden Vorschriften enthalten".

${ }^{69}$ En efecto, esa regulación se sitúa, dentro del Código Civil, en Libro III, título VIII (Du louage), cuyo capítulo tercero se dedica al arrendamiento de obras y servicios (Du louage d'ouvrage et de service), y cuya primera sección trata del arrendamiento de domésticos y obreros (Du louage des domestiques et ouvriers"); exactamente como en el Code Civil francais.

${ }^{70}$ Art. 2717 : “On ne peut engager ses services qu’à tems, ou pour une entreprise déterminée”. Art. 2718 : "Les domestiques attachés, à la personne du maître, ou au service des maisons, peuvent être renvoyés en tout temps sans expression de cause, et peuvent de même quitter leurs maîtres". Art. 2719. "Les personnes qui ont loué leurs services sur les habitations, ou dans toutes autres manufactures pour y être employées aux travaux qui s'y font, ne peuvent, ni quitter le propriétaire auquel ils se sont loués, ni être renvoyées par eux avant le temps convenu, que pour cause grave". Art. 2720 : "Si hors le cas de cause grave, le propriétaire renvoie la personne qui lui a loué ses services, ainsi qu'il est marqué en l'article précédent, avant l'expiration du tems convenu, il doit lui payer le salarie de l'année ou du temps pour lequel il l'avait louê". Art. 2721. "Si c'est au contraire la personne qui a engagé ainsi ses services, qui quitte le propriétaire, sans cause légitime, il perdra le salaire pour le temps qui s'est écoulé jusqu'alors sur son engagement, ou sera obligé de restituer au propriétaire ce qu'il aura reçu de lui d'avance sur l'année courante, ou sur le temps de l'engagement". [utilizo: Civil Code of the state of Louisiana (New Orleans, E. Johns \& Co, Stationer's Hall, 1938)]. 
lo que haya recibido por adelantado. Como se puede apreciar, y aun cuando se observan algunas diferencias en la formulación de las reglas, parece posible sugerir que estos artículos del Código Civil de Louisiana constituyen la fuente principal de la regulación del Código de Bello, en relación con las que hemos denominado reglas nucleares.

Si se admite, como aquí se sugiere, la influencia inmediata del Código Civil de Louisiana de 1825 en las reglas sobre arrendamiento de criados domésticos del Código de Bello, se vuelve interesante, entonces, considerar cuáles fueron las fuentes del Código Civil de Louisiana, pues estas serán, por tanto, las fuentes mediatas del Código Civil chileno. Al respecto, lo primero que conviene apuntar, es que el contenido de estos artículos 2217 a 2220 CCL es i d é n t i c o al de los artículos 56 a 59 del Digeste de lois civiles de 1808, texto que, aunque sin el nombre de Código, es propiamente el primer Código Civil de Louisiana ${ }^{71}$. De ahí que la pregunta por las fuentes de esta regulación del Código de Louisiana, se traslade a las fuentes del Digeste. Y si analizamos las fuentes del Digeste, siguiendo el orden de importancia que indica Guzmán Brito ${ }^{72}$, podemos detenernos en la primera de ellas: el Proyecto de Código Civil francés de 1800 (en adelante, $P$. Code), sin necesidad de consultar las demás fuentes indicadas. En efecto, en el $P$. Code se contenía una regulación mucho más extensa sobre el louage de domestiques et ouvries que la que finalmente consagró el Code Civil, contenido que corresponde, casi exactamente, y en el mismo orden, al contenido de los artículos 2217 a 2220 del Código Civil de Louisiana; la diferencia es que éste último no recogió ni la primera regla (CX; que corresponde al artículo 1781 Code), ni la última (CXVI del P. Code 1800$)^{73}$.

Otros códigos civiles de la primera mitad del siglo XIX siguieron, en la

${ }^{71}$ Utilizo: A Digest of the Civil Laws now in force in the Territory of Orleans, with alterations and amendments, adapted to its present system of Government (Orleans, Bradford \& Anderson, 1803).

${ }^{72}$ Sobre el punto, Guzmán Brito afirma que el Digeste "es un código que refleja intensamente, tanto el Projet de Code Civil del año VIII (1800), redactado por Portalis, Maleville, Tronchet y Bigot-Prémeneau, cuanto el Code Civil mismo, en un $70 \%$ de sus 3.522 artículos, y desde luego en el sistema $\mathrm{u}$ orden de materias adoptado. El resto reconoce como fuentes a Domat, Pothier, las Siete Partidas, la Nueva Recopilación, el Febrero adicionado de Eugenio Tapia y hasta la Curia Philipica de Hevia Bolaños" [GuZmán Brito, Alejandro, La influencia del Código Civil francés en las codificaciones americanas, en Cuadernos de Extensión Jurídica, 9 (Santiago, Universidad de los Andes, 2004), p. 27].

${ }^{73} \mathrm{CX}$. "Le maître en est cru sur son affirmation : Pour la quotité dés gages, Pour le paiement du salaire de l'année échue, Et pour les acomptes donnés sur l'année courante". CXI. "On ne peut engager ses services qu'à temps, et non pour la vie". CXII. "Les domestiques attachés à la personne du maître ou au service des maisons, peuvent être renvoyés en tout temps sans expression de cause, et peuvent de même quitter leurs maîtres". Por su parte, el CXIII dispone : Les domestiques attachés à la culturelles servantes de cour, les ouvriers artistes, ne peuvent ni quitter leurs maitres, ni être renvoyés par eux, avant le temps convenu, que pour cause grave". CXIV. "Si, hors le cas de cause grave, le maître renvoie son domestique ou son ouvrier avant le temps convenu, il doit lui payer le salaire entier de l'année, ou du temps, pour lequel il l'avait loué, d'éduction faite de la somme que le domestique ou l'ouvrier pourra vraisemblablement; gagner ailleurs pendant le temps qui reste à courir". CXV. "Si c'est le domestique ou l'ouvrier qui quitte sans cause légitime, il doit être condamné, envers le maître, à une indemnité qui est fixée sur ce qu'il en cô̂té de plus au maître pour obtenir d'un autre les mêmes services". CXVI. "L'ouvrier artiste employé à la journée j n'est pas tenu de la 
regulación del arrendamiento de criados domésticos, al Código Civil francés, reproduciendo sus reglas, con algunas diferencias. En este sentido, por ejemplo, el Código Civil holandés de 1838 contiene tres artículos ${ }^{74}$. Los dos primeros (artículos 1637 y 1638) básicamente reproducen los artículos 1780 y 1781 del Code Civi $^{5}$; el tercero, el artículo 1639, agrega una regla que indica que los obreros y domésticos que hubieren celebrado un contrato a plazo no pueden renunciar o ser despedidos sin justa causa; que si se renuncia sin justa causa, pierde todo derecho a su salario; y que, en todo caso, el amo puede despedirlos antes de cumplido el plazo, sin necesidad de alegar motivos, pagando al doméstico el salario de seis semanas $^{76}$. El Código Civil sardo, de 1837, también contiene tres artículos en la sección dedicada al arrendamiento de domésticos y obreros ${ }^{77}$, los dos primeros (artículos 1802 y 1803) reproducen también, y exactamente, los artículos 1780 y 1781 Code $\mathrm{Civil}^{8}$, mientras que el tercero agrega una regla que señala que "se observará además, respecto de los domésticos y obreros, las leyes y reglamentos de policía que les conciernen"79 (similar, por tanto, al artículo 1172 ABGB de 1811), regla que no recoge el Código Civil de Bello.

Por último, sobre la posible influencia que pueda reconocerse al Proyecto de Código Civil español de García Goyena, de 1851 en esta materia, hay que considerar que, por su fecha, sólo podría incidir en el Proyecto Inédito y en el Proyecto de $1853^{80}$. Y la única regla que aparece que aparece a partir del Proyecto

malfaçon de son ouvrage" [utilizo: Projet de Code Civil présenté par la Commission nommée par le Gouvernement le 24 Thermidor an VIII (Paris, 1801)].

${ }^{74}$ Utilizo la reproducción del texto del Código que se contiene en DE SAINT-Joseph, Anthoine, Concordance entre les codes civil étrangers et le Code Napoléon (Paris, 1840).

${ }^{75} \mathrm{La}$ única diferencia es que en el artículo 1638 del Código Civil holandés de 1838, se reproduce el 1781 Code agregando otro punto sobre el cual será creído el amo: la duración del contrato.

${ }^{76}$ Art. $1639 \mathrm{CCH}$ de 1838: [inc. $1^{\circ}$ ] "Les domestiques et autres gens à gage loués à terme, ne peuvent sans cause légitime quitter leur service ni être renvoyés avant l'expiration du terme. [inc. $2^{\circ}$ ] S'il quittent avant l'expiration du terme, ils perdent tout droit à leurs gages. [inc. $3^{\circ}$ ] Néanmoins le maitre pourra les renvoyer avant le terme, sans alléger de motifs, en leur payant, à titre d'indemnité, six semaines de leurs gages à partir du jour où ils cesseront leur service”.

${ }^{77}$ Utilizo: Codice Civile per gli Stati di S.M il Re di Sardegna (Torino, Stamperia Reale, 1837); y para las dos notas que siguen.

${ }^{78}$ Art. 1802 C. Sardegna. "Nessuno può obbligare $i$ suoi servigi che a tempo, o per una determinata impresa". Por su parte, el art. 1803 C. Sardegna: [inc. $1^{\circ}$ ] "Si presta fede al padrone sopra la sua giurata asserzione, [inc. $2^{\circ}$ ] Per la quantità delle mercedi; [inc. $2^{\circ}$ ] Per il pagamento del salario dell'annata scaduta; [inc. $4^{\circ}$ ] E per le somministrazioni fatte in conto dell'anno corrente". Como se puede apreciar, idénticos a los artículos 1780 y 1781 Code.

${ }^{79}$ Art. 1804 C. Sardegna: "Si osserveranno inoltre pei domestici ed operai le leggi e regolamenti particolari di polizia che li riguardano".

${ }^{80}$ Sobre la influencia del Proyecto de García Goyena, véase Rodríguez EnNEs, Luis, Florencio García Goyena y la codificación iberoamericana, en Anuario de Historia del Derecho Español, 76 (2006), pp. 705-726; quien recuerda las palabras de LiRA URQUIETA: "En los años que precedieron a la redacción definitiva de nuestro Código Civil, llegó una espléndida obra española que prestó inapreciables servicios: fue el Proyecto de Código Civil español de García Goyena. A este libro no se le dio en España la resonancia debida. Aparecido en 1852, como fruto de los trabajos codificadores de la Comisión de Juristas que presidía don Florencio García 
de 1853 es la regla del artículo 1995 CC (por la que ha de creerse al amo sobre el criado), que, como ya se ha dicho, está tomada del Code de 1804. Sin embargo, habría que considerar que Bello, conociéndola, no la introdujo en sus primeros proyectos, siendo posible sugerir que el hecho de que la recogiera el proyecto de Goyena, en 1851, pudo haber tenido alguna influencia a la hora de adoptarla también en el Código Civil chileno.

\section{La doctrina de los autores}

Además del derecho vigente, y de los códigos extranjeros, el Mensaje refiere, como fuente relevante en materia de obligaciones y contratos, "la doctrina de alguno de los más eminentes jurisconsultos".

Pues bien, sobre ello, me parece debe descartarse, desde ya, la posible influencia de los comentaristas del Código Civil francés de la primera mitad del siglo XIX, precisamente por el limitado alcance de la regulación que comentan; de hecho, la lectura de los pasajes que dichos autores dedican al arrendamiento de criados domésticos así lo reafirma ${ }^{81}$.

Conviene pues, considerar la posible influencia Pothier, quien, como señala Guzmán "fue sin duda [...] el autor francés que más aportó a los trabajos codificadores; de él Bello citó casi todos sus trabajos civilisticos [...]; la influencia de este jurista, en todo caso, es muy notable en materia de obligaciones y contratos [...]"82. Pothier, en su Traité de Louage, dedica varias páginas a analizar el arrendamiento de criados domésticos. ¿Puede hallarse en Pothier la fuente de alguna de las reglas del Código de Bello, cuyo origen no se halle en las fuentes ya revisadas? Aunque es cierto que todas estas reglas, pueden considerarse derivaciones o especificaciones de otras reglas contenidas en el mismo párrafo, y que, como se ha sugerido, reflejan las características tradicionales de la relación amo-criado, resulta que la lectura de los respectivos pasajes del Traité de Louage de Pothier permite sugerir, verosímilmente, que Bello pudo basarse en Pothier para formular algunas partes de las reglas; en particular: la descripción de las c a us a s g r a e s que autorizan poner término al contrato en forma anticipada; y la regla que exige

Goyena, llegó a Chile pocos meses después y alcanzó a ser utilizado en el llamado Proyecto de 1853 y en el Proyecto de 1855 . Presentaba este libro una ventaja inapreciable que no podían dar las obras españolas restantes, como las de Escriche o Eugenio de Tapia: se tomaban en cuenta no únicamente las leyes castellanas y los fueros, sino también las recientes leyes europeas. Se trataba de un esfuerzo de adaptación encomiable. Es posible que el Proyecto fuera considerado en la Península como algo muy avanzado, y por esa causa se le dejó en la penumbra, más lo cierto es que influyó mucho, y ventajosamente, en el Código Civil chileno" (ibid., p. 720; en nota).

${ }^{81}$ Sobre ello, Guzmán Brito señala que, de ellos, los más relevantes fueron Delvincourt y Rogron [GuZMÁn BRITO, Andrés Bello, cit. (n. 36), p. 424]; de cuyas breves explicaciones, sobre los artículos 1780 y 1781 del Code Civil, ya hemos dado cuenta (supra, nota 62). Y si bien los comentarios de otros autores como Troplong, Duvergier o Duranton, a los que Bello también tuvo acceso, son más extensos, ellos están, en todo caso, limitados también al contenido de las reglas, y su lectura permite descartar su posible influencia en las reglas específicas del Código de Bello [cfr. Duranton, Alexandre, cit. (n. 40) p. p. 237 y ss.; Duvergier, Jean Baptiste, cit. (n. 40) p. 345 y ss.; Troplong, Raymond Théodore, cit. (n. 42), p. 250 y ss.].

${ }^{82}$ GuZmán Brito, Andrés Bello, cit. (n. 36), p. 424. 
al criado permanecer en el servicio, hasta que el amo encuentre un reemplazo; ninguna de las cuales se encuentra en otras fuentes.

En efecto, en relación con la descripción de las causas graves, Pothier se refiere al supuesto del criado que abandona el servicio por el hecho del amo; y señala algunos ejemplos, entre los que indica, expresamente, "los malos tratos del amo, el que le niegue las cosas necesarias para la vida, o si se trata de una criada, porque ha atentado contra su honor". En tales casos, sostiene Pothier, el criado no debe indemnizar al amo, y el amo debe pagar todo el salario hasta completar el plazo del contrato $^{83}$. Se observa que, si bien la consecuencia es diferente a la que prescribe el Código de Bello, las razones que justifican la salida del criado coinciden con la que se señalan en el artículo 1993 CC como causas graves: "mal tratamiento del amo, $i$ cualquier conato de éste o de sus familiares o huéspedes para inducirle a un acto criminal o inmoral". Junto con ello, Pothier también se refiere al caso de que sea el amo quien despida al criado antes del tiempo, por un hecho del criado, y señala como ejemplos, "que haya realizado mal la tarea, que no obedezca al amo, o que le haya faltado el respecto que le debe”, señalando que el tal caso, no puede el criado pretender que se le pague el salario por el tiempo que restaba del contrato; y, en cambio, si el despido fuera sin causa, el amo le debe el salario por todo el tiempo que debía durar el servicio ${ }^{84}$. Como se ve, aunque la consecuencia es diversa, las causas que justifican el despido antes del tiempo coinciden con las que contiene el artículo 1993 CC referidas "la ineptitud del criado" y "a todo acto de infidelidad o insubordinación".

Por otro lado, Pothier, tratando el caso de los servicios que no se prestan a plazo fijo, explica que "a los criados no les está permitido abandonar el servicio del amo sin su licencia, y ellos deben ser condenados a regresar al trabajo, hasta el día en que se acostumbra en el lugar arrendar los servicios, o hasta que el amo tenga tiempo de proporcionarse otro sirviente" ${ }^{\$ 5}$; regla que, sustancialmente,

83 "Lorsque c'est par le fait du maître que le serviteur a quitté son service avant le temps, putà par rapport aux sévices du maître, ou parce qu'il lui refusoit les choses nécessaires à la vie; ou si c'est une servante, parce qu'il a attenté à son honneur, le serviteur peut être admis à la preuve de ces de ces faits; \& s'il les justifie, non-seulement il ne doit pas de dommages \& intérêts à son maître, mais suivant le quatrième de nos principes, son maître n'est pas déchargé envers lui des gages qui restent à courir pour le restant du temps de son service, puisque c'est par le fait du maître qui est le conducteur de ces services qu'il ne les lui rend pas ; c'est pourquoi le maître doit en ce cas payer au serviteur l'année entière de ses services, \& il peut même être condamné aux dommages \& intérêts du domestique" [PотHIER, Robert Joseph, Traité du contrat de louage (Paris/Orleans, 1764), p. 263].

${ }^{84}$ “Lorsque ce n'est pas le serviteur qui a quitté le service de son maître, \& que c'est au contraire le maître qui l'a renvoyé avant l'expiration du temps; si c'est par le fait du serviteur qu'il a été renvoyé, parce qu'il fait de mauvais ouvrage, ou parce qu'il n'obéit pas à son maître, ou parce qu'il manque au respect qu'il lui doit, le serviteur ne peut en ce cas prétendre ses gages pour le temps qui restoit à courir. Mais si le maître l'a renvoyé sans que le serviteur l'ait mérité, le maître lui doit ses gages pour le temps entier que devoit durer son service" [POTHIER, Robert Joseph, cit. (n. 83) p. 164].

85 "Le maître peut les renvoyer quand bon lui semble, \& sans en dire la raison, en leur payant leur service jusqu'au jour qu'il les renvoie. Mais il ne leur est pas permis de quitter le service de leur maître sans son congé \& ils doivent être condamnés à retourner, ou jusqu'au jour du prochain terme auquel il est d'usage dans le lieu de louer les serviteurs, ou feulement jusqu'à ce que le maître ait le temps de se pourvoir d'un autre serviteur" [POTHIER, Robert Joseph, cit. (n. 83) p. 165]. 
corresponde a la del inciso segundo del artículo 1989 CC, que señala "Con todo, si el criado no pudiera retirarse inopinadamente sin grave incomodidad o perjuicio del año, será obligado a permanecer en el servicio el tiempo necesario para que pueda ser reemplazado, aunque no se haya estipulado desahucio".

\section{CONCLUSIONES}

La investigación de la que se ha dado cuenta en este trabajo permite, en síntesis, proponer las siguientes conclusiones:

1.En relación con la estructura de la regulación entre amos y criados, la aproximación del Código Civil de Bello, de tratar estas relaciones como un contrato; y particularmente, como un contrato de arrendamiento, puede considerarse como la conservación del modelo romano de la locatio conductio, modelo que, desde el punto de vista jurídico, era el modelo vigente (al estar presente en las Siete Partidas), y que también había conservado el Código Civil francés de 1804. Sin perjuicio de estimarse que esa es la principal razón, tal aproximación puede, también, explicarse desde la perspectiva de la filosofía liberal, que considera a ambas partes como libres e iguales para acordar los términos de la relación de trabajo doméstico.

2. En relación con el contenido de la regulación, se trata de una regulación más bien limitada, tanto en su extensión (pocos artículos) como en su contenido (casi todas las reglas se refieren a la terminación del contrato). Si bien, esta regulación no termina de despojarse de las características que tradicionalmente definieron la relación amo-criado, ella tiene, al mismo tiempo, un cierto carácter moderno, que puede estimarse reflejo de los cambios sociales que se observan ya hacia mediados del siglo XIX, pues entiende la relación amo-criado como una relación de origen contractual, que se celebra sobre la base de un salario, en la que las partes contratantes son formalmente iguales y libres para celebrar el contrato y determinar su contenido; a la vez que se limita su duración y se establecen condiciones de salida unilateral para ambas partes.

3. Si uno analiza la evolución del párrafo, a lo largo de los diferentes proyectos de Código Civil, se observan varios y significativos cambios. Un cambio relevante es el del ámbito de aplicación de la regulación, que a partir del Proyecto Inédito se limita a los criados domésticos, a diferencia de las propuestas contenidas en los proyectos anteriores, que regulaban el arriendo de "criados" y de "obreros", conjuntamente, como ocurre en el Code civil de 1804. Este es, desde luego, un punto original de la regulación. Por otro lado, ese estudio de los proyectos permite identificar un núcleo de regulación, relativo a ciertas reglas básicas sobre la terminación del contrato, que se encuentran contenidos ya en el primer proyecto. En relación con las fuentes de ese núcleo de la regulación, la investigación aquí realizada permite s u g e r i r ve rosím il me n t e una marcada influencia del Código Civil de Louisiana de 1825, que básicamente reprodujo las reglas del Digeste de lois civiles de Orleans, de 1808, y que, a su vez, reconoce como fuente, en esta materia, el Proyecto de Código Civil francés de 1800.

4. Fuera de ese núcleo de reglas sobre terminación, tenemos otras dos reglas 
que fueron introducidas tardíamente en el proceso de codificación. La regla que señala que la muerte del amo no pone fin al contrato (que aparece en el Proyecto Inédito) y la regla del artículo $1995 \mathrm{CC}$, por la que ha de creerse al amo respecto del monto de salario, el hecho de su pago o de adelantos hechos al criado (que aparece en el Proyecto de 1853). La primera, como se ha mostrado, está presente en las Partidas, siguiendo las fuentes romanas; y su derivación implícita (la muerte del criado sí pone fin al contrato) es simplemente una excepción lógica de la regla de transmisibilidad que afecta a los contratos intuito personae, también reconocida por la doctrina romanista. La segunda regla está tomada, sin duda alguna, del artículo 1781 del Código Civil francés; aunque el hecho de que no se haya recogido en los primeros proyectos permite sugerir alguna influencia de otros Códigos o textos posteriores que también la recogieron, entre ellos, el Proyecto de Código Civil de García Goyena.

5. Las otras reglas del párrafo parecen ser originales de Bello; no se encuentran reglas parecidas en ninguna de las fuentes normativo-dogmáticas del Código Civil. En relación con estas reglas, desde un punto de vista formal es posible afirmar que se trata de reglas derivadas o especificaciones de otras reglas, que ya estaban contenidas en el núcleo central original de la regulación. En efecto, la regla de la nodriza (art. 1990 CC), por ejemplo, se presenta como derivación de la regla contenida en el art. 1988 CC; y la regla que impone respetar el plazo del desahucio, parece una derivación de la regla del artículo 1993 CC, que contiene el principio de que el plazo del contrato es obligatorio. Ello, desde luego, sin perjuicio de que es posible sugerir que estas reglas "originales" fueron inspiradas o se justificaron en consideración de lo que el propio Mensaje del Código civil denomina "la práctica del país", una cuestión que invita a realizar un análisis a fondo.

\section{BiBLIOGRAFÍA}

AraYA, Alejandra, Sirvientes contra amos: Las heridas en lo intimo propio, en GaZMURI, Cristián; Sagredo, Rafael (eds.), Historia de la vida privada en Chile (Santiago, Ed. Taurus, 2005), I, pp. 161-197.

Amunátegui Reyes, Miguel Luis, Andrés Bello y el Código Civil (Santiago, Imprenta Cervantes, 1883).

Bello, Andrés, Obras completas. Vol. XI: Proyectos de Código Civil (Santiago, Pedro

G. Ramírez, 1887); Vol. XII: Proyectos de Código Civil (1853), (Santiago, Pedro

G. Ramírez, 1888); Vol. XIII: Proyecto Inédito de Código Civil (Santiago, Pedro G.

Ramírez, 1890); Vol. XVII. Derecho romano (2a ed., Caracas, Fundación La Casa de Bello, 1981); Vol. XVIII. Temas jurídicos y sociales (2a ed., Caracas, Fundación La Casa de Bello, 1981); Vol. XXI. Temas educacionales (2a ed., Caracas, Fundación La Casa de Bello, 1981).

Bentham, Jeremías, Tratado de legislación civily penal (Paris, 1838, trad. Ramón Salas). Bravo Lira, Bernardino, Vigencia de las Partidas en Chile, en Revista de Estudios Histórico-Jurídicos, 10 (1985), pp. 43-105.

Castaldo, André, L'histoire juridique de l'article 1781 du Code Civil: "Le maître est cru sur son affirmation", en Revue Historique de Droit Français et Étranger, 55/2 (1977), pp. 211-237. 
Cavieres Figueroa, Eduardo, Liberalismo: ideas, sociedad y economía en el siglo XIX (Valparaíso, Ediciones Universitarias de Valparaíso, 2016).

Concha, Juan Enrique, Cuestiones obreras, en Grez Toso, Sergio, La "cuestión social" en Chile. Ideas y debates precursores (1804-1922), (Santiago, Dirección de Bibliotecas, archivos y museos, 1995), pp. 456-517 (originalmente publicado por Imprenta, Litografía y encuadernación Barcelona, Santiago, 1889).

Collier, Simon, Chile. La construcción de una República. 1830-1865. Politica e ideas ( $2^{a}$ ed., Santiago, Ediciones de la Universidad Católica de Chile, 2008).

Delvincourt, Claude-Étienne, Cours de Code Napoléon (Paris, 1813).

De Maleville, Jacques, Analyse raissonée de la discussion du Code Civil au conseil d'Etat (Paris, 1822).

De Saint-Joseph, Anthoine, Concordance entre les codes civil étrangers et le Code Napoléon (Paris, 1840).

Duranton, Alexandre, Cours de droit civil suivant le code français (4ª ed., Bruxelles, 1841,), XVII.

Duvergier, Jean-Baptiste, Le droit civil français suivant l'ordre du Code. Continuation de Toullier (5a ed., Paris, 1838).

ERbetta Mattig, Andrés, La cesación unilateral del contrato de obra prevista en el art. 1999 inc. $2^{\circ}$ del Código Civil, en Revista Chilena de Derecho Privado, 28 (2017), pp. $9-51$.

Feliu Cruz, Guillermo, La abolición de la esclavitud en Chile. Estudio Histórico y social (2a ed., Santiago, Editorial Universitaria, 1973).

GonZÁlez LE SAUX, Marianne, Tienda, botica, fábrica, taller, posada y escuela. La clase media en las disposiciones patrimoniales del Código Civil chileno de 1855, en Estudios de la República (2011), pp. 1-49.

Grez Toso, Sergio, De la "Regeneración del Pueblo" a la huelga general. Génesis y evolución histórica del movimiento popular en Chile (1810-1890) (Santiago, Ril Editores, 2007).

GuZmán Brito, Alejandro, Algunas actas de sesiones de la comisión revisora del Código Civil, en Revista de Estudios Histórico-Jurídicos, 5 (1980), pp. 413-418.

-Andrés Bello codificador. Historia de la fijación y codificación del derecho civil en Chile (Santiago, Ediciones de la Universidad de Chile, 1982).

- La influencia del Código Civil francés en las codificaciones americanas, en Cuadernos de Extensión Jurídica, 9 (Santiago Universidad de los Andes, 2004), pp. 17-50.

Humeres Noguer, Héctor, Apuntes de derecho del trabajo y de la seguridad social (10a ed., Santiago, Editorial Jurídica de Chile, 1973).

JaKsic, Iván, Andres Bello: la pasión por el orden ( $3^{\mathrm{a}}$ ed., Santiago de Chile, Editorial Universitaria, 2010).

LABARCA GODDARD, Eduardo, El concepto de patrón o empleador en la legislación chilena (Santiago, Jurídica de Chile, 1966).

Lasso GaITE, Juan Francisco, Crónica de la codificación española, IV: Codificación civil (Génesis e historia del Código), (Madrid, 1970), II/1-2.

Martin Casares, Aurelia, Domestic Service in Spain. Legislation, Gender and Social Practice, en Fauve-Chamoux, Antoinette (ed.), Domestic Service and the formation of European Identity. Understanding the Globalization of Domestic Work, 16th-21st Centuries (Bern, Peter Lang, 2004), pp. 189-209.

Mondaca Miranda, Alexis, Evolución del pensamiento de Andrés Bello sobre el carácter gratuito u oneroso del contrato de mandato, en Revista de Estudios Histórico-Jurídicos, 41 (2019), pp. 317-340. 
PéReZ, Francisco Javier, El diccionario y los diccionarios en la obra de Andrés Bello. Teoría, critica y elaboración lexicográficas, en Boletín de Filologia, 49/1 (2014), pp. 107-133.

Petrt, Carlos, Un Código Civil perfecto y bien calculado. El proyecto de 1821 en la historia de la codificación (Madrid, Dykinson, 2019).

Pothier, Robert Joseph, Traité du contrat de louage (Paris/Orleans, 1764)

Real Academia Española, Diccionario de la lengua castellana (10a ed., Madrid, Imprenta Nacional, 1852).

RODRíguez ENNES, Luis, El singular renacimiento de la autonomía de la voluntad y la "locatio conductio operarum et operis" como consecuencia de la presente depresión económica, en Revista de Derecho de la Pontificia Universidad Católica de Valparaíso, 32 (2009), pp. 183-208.

-Florencio García Goyena y la codificación iberoamericana, en Anuario de Historia del Derecho Español, 76 (2006), pp. 705-726.

Rogron, Joseph-André, Codes français expliqués, par leurs motifs, par des exemples, et par la jurisprudence, suivis des formulaires (Paris, 1836).

Romero, Luis Alberto, ¿Qué hacer con los pobres? Elites y sectores populares en Santiago de Chile 1840-1895 (Santiago, Ariadna Ediciones, 2007).

Salinas Araneda, Carlos, Notas en torno a las actas de los proyectos de Código Civil, en Revista de Derecho de la Pontificia Universidad Católica de Valparaiso, 1 (1977), pp. 33-41.

SEVERIN Fuster, Gonzalo, Sobre el modelo de contratación de servicios remunerados en el derecho romano. Algunos aspectos relevantes de la "locatio conductio", en Revista de Derecho de la Universidad Católica del Norte (RDUCN), 22/2 (2015), pp. 357-389.

- La recepción del modelo de la "locatio conductio" en la regulación del arrendamiento de obras y servicios del Código Civil español de 1889, en Revista de Estudios Histórico-Jurídicos, 38 (2016), pp. 201-223.

Solano, Sergio, Entre el Código Civil y el Código de Policía. Trabajo, orden doméstico y legislación laboral en el Caribe colombiano en el siglo XIX, en Revista Gaceta Laboral, 16/2 (2010), pp. 147-174.

SolÉ Resina, Judith, Arrendamiento de obras o servicios (perfll evolutivo y jurisprudencial) (Valencia, Tirant Lo Blanch, 1997).

Thayer Arteaga, William, El trabajador en la historia del derecho laboral chileno, en Revista Chilena de Derecho, 16/3 (1989), pp. 763-776.

Torres Lana, José Ángel, Comentarios de los art. 1583-1587, en PaZ-Ares, Cándido et al. (dirs.), Comentario del Código Civil (Madrid, Ministerio de Justicia, 1993), pp. 1170-1174.

TROPLOnG, Raymond Théodore, Le droit civil expliqué suivant l'ordre des articles du Code: De l'échange et du louage, (Bruxelles, 1841).

Villasamil Prieto, Humberto, Pasado y presente del derecho laboral latinoamericano y las vicisitudes de la relación de trabajo (primera parte), en Revista Latinoamericana de Derecho Social, 21 (julio-diciembren 2015), pp. 203-228.

WALKER LinARES, Francisco, Esquema del derecho del trabajo y de la seguridad social en Chile (Santiago, Editorial Jurídica de Chile, 1965).

Zimmermann, Reinhard, The Law of Obligations. Roman foundations of the civilian tradition (1990, reimp. Cape Town, Juta and Co., 1992). 